Article

\title{
Influences of Substrate Temperatures and Oxygen Partial Pressures on the Crystal Structure, Morphology and Luminescence Properties of Pulsed Laser Deposited $\mathrm{Bi}_{2} \mathrm{O}_{3}: \mathrm{Ho}^{3+}$ Thin Films
}

\author{
Divya Janardhana ${ }^{1,2}$, Shivaramu N. Jayaramu ${ }^{1}$, Wiets D. Roos ${ }^{1} \oplus$, Walter Purcell ${ }^{2}$ \\ and Hendrik C. Swart ${ }^{1, *(D)}$ \\ 1 Department of Physics, University of the Free State, Bloemfontein ZA-9300, South Africa; \\ divyajanardhan03@gmail.com (D.J.); nj.shivaram@gmail.com (S.N.J.); rooswd@ufs.ac.za (W.D.R.) \\ 2 Department of Chemistry, University of the Free State, Bloemfontein ZA-9300, South Africa; \\ PurcellW@ufs.ac.za \\ * Correspondence: swarthc@ufs.ac.za
}

Received: 12 November 2020; Accepted: 25 November 2020; Published: 29 November 2020

\begin{abstract}
Monoclinic $\mathrm{Bi}_{2} \mathrm{O}_{3}: \mathrm{Ho}^{3+}$ powder was synthesized using a co-precipitation method, followed by the deposition of $\mathrm{Bi}_{2} \mathrm{O}_{3}: \mathrm{Ho}^{3+}$ thin films on $\mathrm{Si}(100)$ substrates at various substrate temperatures (room temperature- $600{ }^{\circ} \mathrm{C}$ ) and oxygen partial pressures (5-200 $\mathrm{mT}$ ) using pulsed-laser deposition. X-ray diffraction analysis showed a single $\alpha-\mathrm{Bi}_{2} \mathrm{O}_{3}$ phase at temperatures of 400 and $500{ }^{\circ} \mathrm{C}$, while a mixed $\alpha$ - and $\beta-\mathrm{Bi}_{2} \mathrm{O}_{3}$ phase was obtained at $600{ }^{\circ} \mathrm{C}$. The films deposited at the different oxygen partial pressures showed an $\alpha-\mathrm{Bi}_{2} \mathrm{O}_{3}$ and non-stoichiometric phase. The influences of different substrate temperatures and oxygen partial pressures on the morphology and the thickness of the films were analyzed using a scanning electron microscope. The root mean square roughnesses of the films were determined by using an atomic force microscope. The surface components, oxidation states and oxygen vacancies in all the deposited thin films were identified by $\mathrm{X}$-ray photoelectron spectroscopy. The optical band gap of the $\mathrm{Bi}_{2} \mathrm{O}_{3}: \mathrm{Ho}^{3+}$ thin films was calculated using diffused reflectance spectra and was found to vary between 2.89 and $2.18 \mathrm{eV}$ for the deposited films at the different temperatures, whereas the different oxygen partial pressures showed a band gap variation between 2.97 and $2.47 \mathrm{eV}$. Photoluminescence revealed that $\mathrm{Ho}^{3+}$ was the emitting centre in the isolated thin films with the ${ }^{5} \mathrm{~F}_{4} /{ }^{5} \mathrm{~S}_{2} \rightarrow{ }^{5} \mathrm{I}_{8}$ transition as the most intense emission in the green region.
\end{abstract}

Keywords: $\mathrm{Bi}_{2} \mathrm{O}_{3}: \mathrm{Ho}^{3+}$ thin films; X-ray diffraction; scanning electron microscopy; X-ray photoelectron spectroscopy; photoluminescence

\section{Introduction}

The recent popularity of $\mathrm{Bi}_{2} \mathrm{O}_{3}$ as a p-type semiconductor as a research topic, is mainly due to its attractive physical properties, which include wide optical bandgap energies that range from about 2.0 to $3.9 \mathrm{eV}$, high dielectric permittivity, good photocatalytic activity, high refractive index, oxide ion conductivity and good photoluminescence (PL) $[1,2] . \mathrm{Bi}_{2} \mathrm{O}_{3}$ also has the potential to be used in a number of modern applications, including their applications as supercapacitors, optical coatings, optoelectronic devices, gas sensors, microwave integrated circuits, solar cells, etc. [3,4].

It is common knowledge that $\mathrm{Bi}_{2} \mathrm{O}_{3}$ has five different polymorphic forms that are denoted as $\alpha-\mathrm{Bi}_{2} \mathrm{O}_{3}$ (monoclinic), $\beta-\mathrm{Bi}_{2} \mathrm{O}_{3}$ (tetragonal), $\gamma-\mathrm{Bi}_{2} \mathrm{O}_{3}$ (body centred cubic), $\delta-\mathrm{Bi}_{2} \mathrm{O}_{3}$ (face centred cubic) and $\varepsilon-\mathrm{Bi}_{2} \mathrm{O}_{3}$ (orthorhombic) [3,4]. The $\alpha-\mathrm{Bi}_{2} \mathrm{O}_{3}$ phase is the favourite research candidate amongst the different polymorphic forms, due to its high refractive index, good photocatalytic activity and 
stability at room temperature, while the $\alpha-\mathrm{Bi}_{2} \mathrm{O}_{3}$ nanostructure is well-known as a visible light active semiconductor. This makes it a very suitable candidate for solid-state white lightening optoelectronics, optical switches, ultra-short pulse generators and nonlinear optical fibre devices [1,5-7]. The $\beta-\mathrm{Bi}_{2} \mathrm{O}_{3}$ on the other hand, has shown tremendous potential in photo-electrochemical and photocatalytic applications [8].

Research literature indicates that the $\mathrm{Bi}_{2} \mathrm{O}_{3}$ films have been prepared by various methods, such as the vapor transport method [7], spray pyrolysis technique, pulsed laser deposition (PLD), chemical vapor deposition (CVD), sputtering, electro-deposition and sol-gel technique [6]. Reported results indicate that it is possible to grow good quality oxide films at comparatively low substrate temperatures with PLD without the need for annealing treatment. These films exhibit highly textured morphologies with improved orientation which increases the probability of growing better quality thin films with improved luminescence and optical properties. In addition, PLD also has the potential to deposit various thicknesses of the films, which opens up the opportunity for the simultaneous use of several distinct materials as targets and the opportunity for the in situ deposition of hetero-structures with atomic precision or with complex oxides. [9,10]. Recent articles on the use of PLD for $\mathrm{Bi}_{2} \mathrm{O}_{3}$ thin film deposition reported cost-efficient $\mathrm{BK} 7$ glass slide deposition with substrate temperatures ranging between 300 and $600{ }^{\circ} \mathrm{C}$ and included a report on the crystal structure, morphology and optical properties of the deposited material. Results which indicated the formation of various energy bandgap values for the different films may have useful applications in several optoelectronics industries [11].

PL is also a very useful technique to investigate the structure, the electronic band transitions and the intrinsic and extrinsic defects of these deposited materials [12], and has extensively been used to study the optical variations of $\alpha-\mathrm{Bi}_{2} \mathrm{O}_{3}$ which can potentially be used in numerous applications [12-14]. $\mathrm{Li}$ et al. [15] reported the layer-by-layer assembly preparation of thin-film $\mathrm{Bi}_{2} \mathrm{O}_{3}$. The excitation spectra of these $\mathrm{Bi}_{2} \mathrm{O}_{3}$ films indicated a very characteristic and intense peak at $390 \mathrm{~nm}$, which was very close to the $388 \mathrm{~nm}$ band $(3.2 \mathrm{eV})$, which is normally attributed to the band gap of excited $\mathrm{Bi}_{2} \mathrm{O}_{3}$. The strong green emission of $\mathrm{Bi}_{2} \mathrm{O}_{3}$ is ascribed to intraionic transitions in $\mathrm{Bi}^{3+}\left({ }^{3} \mathrm{P}_{1}-{ }^{-1} \mathrm{~S}_{0}\right.$ transitions) [16-18]. The weak emission intensity of $\mathrm{Bi}$ ions in $\mathrm{Bi}_{2} \mathrm{O}_{3}$ restricts its application as a light emitting phosphor $[13,19,20]$. Research, however, proved that the doping of $\mathrm{Bi}_{2} \mathrm{O}_{3}$ with rare earths (REs) enhances the PL properties of $\mathrm{Bi}_{2} \mathrm{O}_{3}$ nanocrystals in the visible to infrared region [1,2]. It is well known that the excitation of $\mathrm{RE}$ ions in the UV-visible region results in the emittance of sharp emissions bands in the ultraviolet to the far infrared region due to their $4 \mathrm{f}-4 \mathrm{f}$ or $5 \mathrm{~d}-4 \mathrm{f}$ transitions $[1,2,20]$. Research confirmed that the inclusion of $\mathrm{RE}$ ions into the $\mathrm{Bi}_{2} \mathrm{O}_{3}$ crystal lattice improved the luminescence properties of the $\mathrm{Bi}$ nanocrystals [2]. Among the RE ions, holmium $\left(\mathrm{Ho}^{3+}\right)$ is one of the desirable candidates to be used as an activator because of its favourable energy level structure and multiple meta-stable energy levels [21]. $\mathrm{Ho}^{3+}$ ions are used for laser action at different wavelengths, from $550 \mathrm{~nm}$ to $3.9 \mu \mathrm{m}$, in a variety of hosts [22]. Results obtained by Premkumar et al. [23] indicated that the inclusion of $\mathrm{Ho}^{3+}$ into a $\mathrm{YAlO}_{3}$ nanophosphor produced multiple meta-stable $\mathrm{Ho}^{3+}$ energy levels due to the complexity of its $4 \mathrm{f}^{10}$ energy level system, which produced multiple emissions at various wavelengths ranging from the visible to the infrared region [1,23]. The green emission, which dominates the blue and red emissions, is attributed to the ${ }^{5} \mathrm{~F}_{4} /{ }^{5} \mathrm{~S}_{2} \rightarrow{ }^{5} \mathrm{I}_{8}$ transitions present in the $\mathrm{Ho}^{3+}$. This intense green luminescence can be used in the lamp industry, in cathode ray tube (CRT) manufacturing, as field emission displays (FEDs), in security printing and even in biologically-oriented applications [24-27]. Additionally, the NIR emissions may have applications in remote sensing, military applications and weather forecasting, or for atmospheric pollution detection [28,29]. In addition, the ionic radius of the $\mathrm{Ho}^{3+}$ ion $(0.90 \AA)$ is nearly equal to that of the $\mathrm{Bi}^{3+}$ ion $\left(1.03 \AA\right.$ ) in $\mathrm{Bi}_{2} \mathrm{O}_{3}$ [30]; therefore, the $\mathrm{Ho}^{3+}$ ions are easily substituted into $\mathrm{Bi}^{3+}$ in the $\mathrm{Bi}_{2} \mathrm{O}_{3}$ crystal lattice without any charge compensation. In our pervious study we reported on the structural, optical, photoluminescence and photocatalytic properties of the monoclinic $\mathrm{Bi}_{2} \mathrm{O}_{3}: \mathrm{Ho}^{3+}$ nanopowder that was synthesized by the co-precipitation method, which showed a strong green emission with greater photocatalytic activity for degradation of organic dye under UV-Vis light [1]. There are only a few reports on optical and luminescence studies of RE-ion-doped $\mathrm{Bi}_{2} \mathrm{O}_{3}$ 
thin films [10,31]. Due to the strong green emission of the obtained powder [1], it was necessary to also try to obtain efficient thin films for the different applications, especially flat panel displays (FPDs). Thin film phosphor materials have some advantages over powders in the FED environment, such as the reduction of light scattering and the good thermal contact between the screen and the faceplate [32,33]. The laser deposition technique has advantages over other deposition methods, because it is a purely physical mechanism without the incorporation of carbon and the stoichiometry of the target material is maintained in the deposited films [34]. The thickness and the surface morphology can be controlled by varying, among the growth parameters, the number of laser pulses and the ambient gas pressure in the deposition chamber [35].

This study investigated the PLD deposition of $\mathrm{Bi}_{2} \mathrm{O}_{3}: \mathrm{Ho}^{3+}$ thin films on silicon (100) substrates. The effects of deposition substrate temperatures and oxygen partial pressures on the as-prepared films' structural, morphological, compositional, optical and luminescence properties were systematically investigated. The surface chemical states were studied by X-ray photoelectron spectroscopy (XPS), while the resulting crystal features, morphology, surface contaminations and oxygen vacancies were correlated with the PL results. The first step was to understand the material characteristics and to determine the correlations between the deposition parameters and photoluminescence properties of the $\mathrm{Bi}_{2} \mathrm{O}_{3}: \mathrm{Ho}^{3+}$ thin films. No work has not yet been reported on the luminescence studies of $\mathrm{Ho}^{3+}$-doped $\mathrm{Bi}_{2} \mathrm{O}_{3}$ thin films. Optimization of the deposition parameters is very important in the study of luminescent thin films. Therefore, we examined the conditions under which strong PL from $\mathrm{Bi}_{2} \mathrm{O}_{3}: \mathrm{Ho}^{3+}$ was observed.

\section{Materials and Methods}

For the pellet preparation, 1 mol. $\% \mathrm{Bi}_{2} \mathrm{O}_{3}: \mathrm{Ho}^{3+}$ powder was prepared by co-precipitation. The detailed preparation of $\mathrm{Bi}_{2} \mathrm{O}_{3}: \mathrm{Ho}^{3+}$ was described in a previous study [1]. The prepared powder was annealed at $300{ }^{\circ} \mathrm{C}$ for $2 \mathrm{~h}$ in air at the furnace heating rate of $5^{\circ} \mathrm{C} / \mathrm{min}$ in order to improve its stoichiometry and crystallinity $[9,10]$. Approximately $10 \mathrm{~g}$ of the annealed powder was pressed (12 ton) as a $25 \mathrm{~mm}$ diameter disk, using a hydraulic press. The disks were introduced into a PLD chamber and placed in a target holder which was rotated at 10 degrees/min to avoid laser-pinning.

$\mathrm{Si}$ (100) substrate was cut into pieces of $\approx 3 \mathrm{~cm} \times 2 \mathrm{~cm}$. The substrates pieces were ultrasonically cleaned for about $5 \mathrm{~min}$ using acetone, ethanol and then distilled water. The substrates were then dried with a stream of nitrogen gas and placed in the PLD chamber. The temperature in the PLD chamber was kept constant at RT, 200, 300, 400, 500 and $600^{\circ} \mathrm{C}$ during the ablation process while a vacuum base pressure of $\approx 2.6 \times 10^{-5} \mathrm{~T}$ was maintained in the PLD chamber during the deposition of the films. A $266 \mathrm{~nm} \mathrm{Nd:YAG} \mathrm{laser} \mathrm{was} \mathrm{used} \mathrm{for} \mathrm{the} \mathrm{ablation} \mathrm{and} \mathrm{the} \mathrm{substrate-target} \mathrm{distance} \mathrm{was} \mathrm{maintained} \mathrm{at}$ $5 \mathrm{~cm}$ for all samples. The laser energy, time of deposition and ablated area were fixed at $50 \mathrm{~mJ}, 15 \mathrm{~min}$ and $1.5 \mathrm{~mm}$, respectively. The chamber was also back filled with oxygen at partial pressures of 5, 20, 100 and $200 \mathrm{mT}$ while the substrate temperature was kept constant at $400{ }^{\circ} \mathrm{C}$.

The crystal structural properties of the $\mathrm{Bi}_{2} \mathrm{O}_{3}: \mathrm{Ho}^{3+}$ thin films were analysed with a Bruker D8 Advance X-ray diffractometer (XRD, Billerica, MA, USA) using $\mathrm{Cu} \mathrm{K} \alpha$ radiation $(\lambda=0.154 \mathrm{~nm}$ ). The surface morphologies of the deposited films were analyzed by a field emission scanning electron microscope (FESEM) using a JEOL JSM-7800F microscope (Tokyo, Japan) and a Shimadzu atomic force microscope (AFM) Model SPM-9600 (Tokyo, Japan). The FESEM was equipped with an energy dispersive X-ray spectrometer (EDS) and was used for the quantification of elements present in the deposited films. The diffuse reflectance (DR) spectral measurements were recorded using a Perkin Elmer Lambda 950 UV-Vis spectrophotometer (Waltham, MA, USA) with an integrating sphere. The XPS measurements were performed using a PHI 5400 XPS spectrometer (Chanhassen, MN, USA) with a non-monochromatic $\mathrm{Mg} \mathrm{K} \alpha$ X-ray source $(1253.6 \mathrm{eV})$, operating at $300 \mathrm{~W}$ and $15 \mathrm{kV}$, and a hemispherical sector analyser. The photoelectron take-off angle measurements were done at $45^{\circ}$. Survey scans were monitored with an energy sweep of $178.95 \mathrm{eV}$ in steps of $0.25 \mathrm{eV}$ and dwell time of $100 \mathrm{~ms}$. High resolution scans used an energy sweep of $44.75 \mathrm{eV}$ and a step size $0.125 \mathrm{eV}$. Charge 
corrections were applied using the $\mathrm{C}-\mathrm{C}$ bond with a binding energy of $284.7 \mathrm{eV}$ as reference, and the high resolution XPS spectra were deconvoluted using XPS PEAK 4.1 software. PL measurements were carried out with an Edinburgh Instruments FLS980 system (Livingston, UK) equipped with dual monochromators and excitation was achieved with a $450 \mathrm{~W}$ steady-state Xe lamp.

\section{Results}

The XRD patterns in Figure 1 show the as-deposited $\mathrm{Bi}_{2} \mathrm{O}_{3}: \mathrm{Ho}^{3+}$ films on the substrates at different temperatures $\left(\mathrm{T}_{\mathrm{S}}\right)$ which ranged between $\mathrm{RT}$ and $600^{\circ} \mathrm{C}$. The maximum diffraction peaks of the RT film indicated the presence of monoclinic $\alpha-\mathrm{Bi}_{2} \mathrm{O}_{3}$ (JCPDS card 71-2274), with the main one situated at $2 \theta=27.3^{\circ}(\overline{1} 21)$ and a non-stoichiometric of $\mathrm{Bi}_{2} \mathrm{O}_{2.3}$ phase peak at 29.2 ${ }^{\circ}$ (JCPDS card number 76-2477). However, the XRD pattern of the film obtained for the $\mathrm{T}_{\mathrm{S}}$ at $200^{\circ} \mathrm{C}$ consisted of a mixture of Bi metal diffraction peaks at $2 \theta=22.6^{\circ}, 38.03^{\circ}$ and $39.71^{\circ}$ (JCPDS card number $85-0051$ ), and $\beta-\mathrm{Bi}_{2} \mathrm{O}_{3}$ peaks at $2 \theta$ $=31.6^{\circ}$ and $44.5^{\circ}$ (JCPDS card number 74-1331) indicating the presence of the non-stoichiometric $\mathrm{Bi}_{2} \mathrm{O}_{2.3}$ phase and the predominant presence of the $\alpha-\mathrm{Bi}_{2} \mathrm{O}_{3}$ phase. The XRD pattern of the $\mathrm{T}_{\mathrm{S}}$ at $300{ }^{\circ} \mathrm{C}$ showed the presence of $\alpha-\mathrm{Bi}_{2} \mathrm{O}_{3}$ phase accompanied by peaks attributed to Bi metal and non-stoichiometric phases. At this temperature, the $\beta$-phase peaks and some Bi metal peaks at $2 \theta=38.03^{\circ}$ and $39.71^{\circ}$ disappeared, and a new $\alpha-\mathrm{Bi}_{2} \mathrm{O}_{3}$ peak appeared at $57.9^{\circ}$. At 400 and $500{ }^{\circ} \mathrm{C}$ only a single $\alpha-\mathrm{Bi}_{2} \mathrm{O}_{3}$ phase product was observed, suggesting the complete oxidation of the bismuth thin films [36,37]. A further increase of $\mathrm{T}_{\mathrm{S}}$ to $600{ }^{\circ} \mathrm{C}$ again led to the formation of mixed $\alpha-, \beta-\mathrm{Bi}_{2} \mathrm{O}_{3}$ phases with the $\beta-\mathrm{Bi}_{2} \mathrm{O}_{3}$ peaks positioned at $2 \theta=11.5^{\circ}, 23.0^{\circ}$ and $29.3^{\circ}$ (JCPDS card number 74-2351). The results also indicate that the $\beta-\mathrm{Bi}_{2} \mathrm{O}_{3}$ peak positioned at $11.5^{\circ}$ which corresponds to the (200) index plane becomes more prominent at $600{ }^{\circ} \mathrm{C}$. The growth of the tetragonal $\mathrm{Bi}_{2} \mathrm{O}_{3}$ phase at $600{ }^{\circ} \mathrm{C}$ was also confirmed by the FESEM image (Figure 4). No additional peaks related to the presence of Ho or any other impurities were detected, and these results indicated that $\alpha-\mathrm{Bi}_{2} \mathrm{O}_{3}$ is thermodynamically stable between 400 and $500{ }^{\circ} \mathrm{C}$ [38].

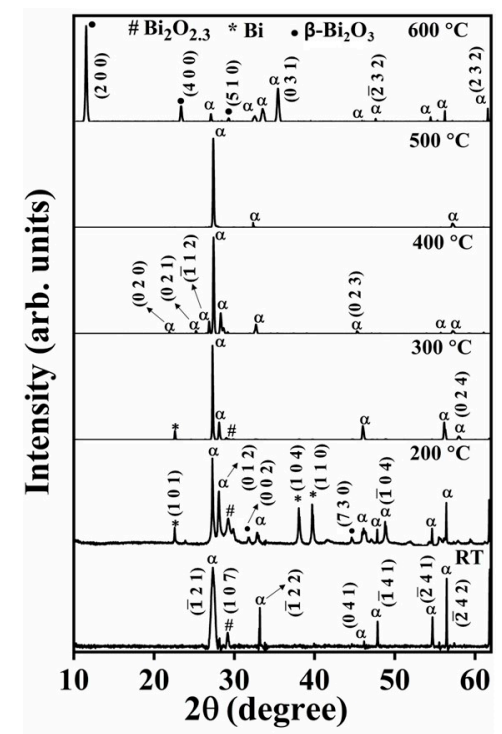

Figure 1. XRD patterns of as-deposited $\mathrm{Bi}_{2} \mathrm{O}_{3}: \mathrm{Ho}^{3+}$ thin films deposited at the different substrate temperatures.

The XRD results indicated that the synthesis of $\alpha-\mathrm{Bi}_{2} \mathrm{O}_{3}$ and mixed $\alpha, \beta$ phases can be achieved by controlling the substrate temperature in vacuo. It is concluded that the high $\mathrm{T}_{\mathrm{S}}$ is not suitable for obtaining pure $\alpha-\mathrm{Bi}_{2} \mathrm{O}_{3}$ thin films. Similar results were reported by Ahila et al. [39], who prepared $\mathrm{Bi}_{2} \mathrm{O}_{3}$ films via a constant potential anodization method, a process by which they thermally evaporated "Bi" layers onto a stainless steel substrate. These thin films were annealed at temperatures between 300 and $600{ }^{\circ} \mathrm{C}$. The resulting layers obtained at 300,400 and $500{ }^{\circ} \mathrm{C}$ showed diffraction peaks that 
correlated well with those of monoclinic $\alpha-\mathrm{Bi}_{2} \mathrm{O}_{3}$. The results obtained for the films annealed at $600{ }^{\circ} \mathrm{C}$, however, indicated the transformation of the $\alpha-\mathrm{Bi}_{2} \mathrm{O}_{3}$ into the $\beta-\mathrm{Bi}_{2} \mathrm{O}_{3}$ phase [39].

The diffraction peak intensity increase in Figure 1, with the increase of the $T_{S}$, is accompanied by a decrease in the peak broadening (better defined), suggesting improvement of the crystallinity of the film at higher temperatures. The crystallite sizes " $\mathrm{D}$ " for the $\mathrm{Bi}_{2} \mathrm{O}_{3}: \mathrm{Ho}^{3+}$ films were calculated using the Scherrer formula [13]. The most prominent peak at $27.3^{\circ}(\overline{1} 21)$ was used for calculating the crystallite sizes for the different temperatures (RT-500 ${ }^{\circ} \mathrm{C}$ ) and peak at $11.5^{\circ}(200)$ was used for $600{ }^{\circ} \mathrm{C}$ calculation. The results indicated that the crystallite size increased from RT to $400{ }^{\circ} \mathrm{C}$ and values of $47,48,49$ and $49.5 \mathrm{~nm}$ were obtained at RT, 200, 300 and $400{ }^{\circ} \mathrm{C}$ respectively. This enhancement of the lattice plane orientation with an increase in temperature is attributed to an increase in the surface diffusion of the adsorbed species, resulting in an improvement in the crystal growth $[40,41]$. Similar results were also observed for $\mathrm{ZnO}$ [42], $\mathrm{ZnO}: \mathrm{Al}$ [43] and $\mathrm{ZnO}: \mathrm{Ga}$ [44]. Further increases in $\mathrm{T}_{\mathrm{S}}$ to 500 and $600{ }^{\circ} \mathrm{C}$ led to decreases of the crystallite size to 49 and $48.8 \mathrm{~nm}$ respectively. A possible reason may be due the poor plane orientation as a result of monoclinic $\mathrm{Bi}_{2} \mathrm{O}_{3}$ decomposition or possibly due to phase transformation from monoclinic $\mathrm{Bi}_{2} \mathrm{O}_{3}$ to tetragonal $\mathrm{Bi}_{2} \mathrm{O}_{3}$ [45].

The XRD patterns of the $\mathrm{Bi}_{2} \mathrm{O}_{3}: \mathrm{Ho}^{3+}$ films deposited on the $\mathrm{Si}$ substrates at $400{ }^{\circ} \mathrm{C}$ and in the presence of different oxygen partial pressures $(5-200 \mathrm{mT})$, are reported in Figure 2. All the diffraction peaks of the films (5-100 mT) indicate mixed $\alpha-\mathrm{Bi}_{2} \mathrm{O}_{3}$ and non-stoichiometric phases of $\mathrm{Bi}_{2} \mathrm{O}_{2.3}$ with different peak intensities. Most of the observed peaks match those of the $\alpha-\mathrm{Bi}_{2} \mathrm{O}_{3}$ phase, (JCPDS card number 71-2274), while the diffraction peaks of the non-stoichiometric phase of $\mathrm{Bi}_{2} \mathrm{O}_{2.3}$ (JCPDS card number 76-2477) were situated at $2 \theta=29.2$ (most intense) and $30.5^{\circ}$. There was also no evidence of the presence of $\mathrm{Bi}$ in metallic phase in these then oxide films. The crystallite sizes of the films also increased stepwise from 40 to 41,43 , and finally $45 \mathrm{~nm}$ as a function of the increases in oxygen pressures from 5 to 20, 100 and finally $200 \mathrm{mT}$ and is attributed to a decrease in intrinsic crystal defects with an increase in the oxygen pressure, resulting in the improved crystallinity [46]. Similar results were reported by Jian et al. [47], who also observed improved $\mathrm{ZnO}$ thin film crystallinity at higher oxygen partial pressures.

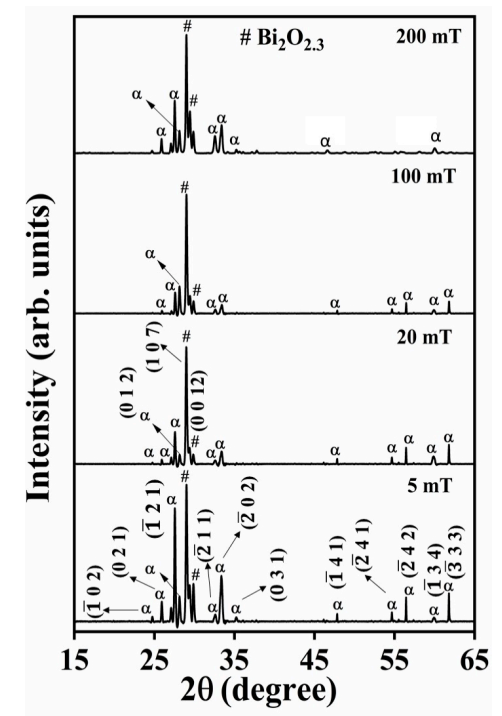

Figure 2. XRD patterns of $\mathrm{Bi}_{2} \mathrm{O}_{3}: \mathrm{Ho}^{3+}$ thin films deposited at the different oxygen partial pressures with constant substrate temperature at $400{ }^{\circ} \mathrm{C}$.

The lattice strain $(\varepsilon)$ was calculated using Equation (1) [48]:

$$
\varepsilon=\frac{\beta \cos \theta}{4}
$$


where, $\beta$ is the full width at half maximum (FWHM) in radians and $\theta$ is the Braggs angle. The value of dislocation density $(\delta)$ is calculated using the Equation (2) [49]:

$$
\delta=\frac{1}{\mathrm{D}^{2}}
$$

The results in Table 1 indicate that the increase in crystallite size is associated with decreases in the strain and dislocation density, resulting in the improvement in the crystallinity of the $\mathrm{Bi}_{2} \mathrm{O}_{3}: \mathrm{Ho}^{3+}$ thin films. The decrease in strain indicates a decrease in crystal defect concentration and the subsequent formation of high quality films. The products isolated at $500{ }^{\circ} \mathrm{C}$ and above indicated a decrease in crystallite size with an increase in strain and dislocation density which could be due to the phase transformation [48].

Table 1. Structural parameters for the $\mathrm{Bi}_{2} \mathrm{O}_{3}: \mathrm{Ho}^{3+}(1 \mathrm{~mol} . \%)$ film deposited at different substrate temperatures.

\begin{tabular}{|c|c|c|c|c|c|}
\hline $\mathrm{T}_{\mathrm{S}}$ & Crystallite Size (D) nm & Strain $(\varepsilon) \times 10^{-4}$ & $\sigma_{\text {Stress }} \mathrm{GPa} \times 10^{-3}$ & Dislocation $(\delta) \times 10^{4}$ Lines $/ \mathrm{m}^{2}$ & $\mathrm{TC}_{\mathrm{hkl}}$ \\
\hline RT & 47.4 & 22.78 & 31.89 & 4.45 & 0.041 \\
\hline $200^{\circ} \mathrm{C}$ & 48.3 & 6.50 & 9.10 & 4.29 & 0.078 \\
\hline $300{ }^{\circ} \mathrm{C}$ & 49.3 & 6.19 & 8.67 & 4.11 & 0.272 \\
\hline $400^{\circ} \mathrm{C}$ & 49.5 & 4.95 & 6.93 & 4.08 & 1.495 \\
\hline $500^{\circ} \mathrm{C}$ & 49.1 & 6.23 & 8.72 & 4.15 & 1.447 \\
\hline $600^{\circ} \mathrm{C}$ & 48.8 & 8.33 & 11.66 & 4.20 & 0.017 \\
\hline
\end{tabular}

The stresses of the prepared films were calculated using the Equation (3) [48]:

$$
\sigma_{\text {stress }}=\frac{\varepsilon}{2} \mathrm{E}
$$

where $\mathrm{E}$ is the Young's modulus of the $\mathrm{Bi}_{2} \mathrm{O}_{3}$ thin film (28 GPa) $[6,49]$ and $\varepsilon$ is the lattice strain. The estimated values of the stress in the films which were grown at the different substrate temperatures are tabulated in Table 1, with a positive sign indicating that the films are in a state of tensile stress. The results clearly indicate that an increase in substrate temperature increased the atomic mobility, and subsequently reduced structural defects and thus caused a decrease in the crystal stress [48]. An increase in stress was observed for the films obtained at $500{ }^{\circ} \mathrm{C}$ and above, possibly due to a change in the morphology of the film [50].

The reflection intensities for each XRD pattern contain extra information related to the preferential or random growth of the polycrystalline thin films. Quantitative information concerning the preferential orientation and texture coefficient $\left(\mathrm{TC}_{\mathrm{hkl}}\right)$ was calculated with Equation (4) [48] and the results are reported in Table 1.

$$
\mathrm{TC}_{\mathrm{hkl}}=\frac{\mathrm{I}_{(\mathrm{hkl})} / \mathrm{I}_{0(\mathrm{hkl})}}{\frac{1}{\mathrm{n}} \sum \mathrm{I}_{(\mathrm{hkl})} / \mathrm{I}_{0(\mathrm{hkl})}}
$$

where $\mathrm{I}_{(\mathrm{hkl})}$ is the measured relative intensity of a plane (hkl) and $\mathrm{I}_{\mathrm{o}(\mathrm{hkl})}$ the standard intensity of the plane (hkl) as taken from JCPDS data, and $\mathrm{n}$ is the total number of reflections. The gradual change of the film texture in a (121) plane was used to evaluate the texture coefficient of each isolated film. The results in Table 1 indicate an increase in texture coefficient which is associated with the substrate temperature increase and reaches a maximum at $400{ }^{\circ} \mathrm{C}$, and then decreases moderately with a further increase to $500{ }^{\circ} \mathrm{C}$, but decreases substantially when the temperature is increased to $600^{\circ} \mathrm{C}$. The calculated texture coefficient for the film deposited at 400 and $500{ }^{\circ} \mathrm{C}$ exceeded one (unity) and is an indication that the film was preferentially oriented along the (121) plane [6,51].

The crystal size, strain, stress and dislocation of the deposited films as functions of $\mathrm{O}_{2}$ partial pressure, are reported in Table 2. The results indicate that the crystallite size increase which is observed is associated with a decrease in the strain, in the stress and in the dislocation density with an increase in the $\mathrm{O}_{2}$ partial pressures. This is indicative of improved crystallinity in the newly formed $\mathrm{Bi}_{2} \mathrm{O}_{3}: \mathrm{Ho}^{3+}$ 
thin films and a decrease in crystal defect concentrations. $\mathrm{TC}_{\mathrm{hkl}}$ values $<1$ were obtained for all the different $\mathrm{O}_{2}$ partial pressures, which implies a lack of grained growth in the hkl direction (( $\left.\overline{1} 21\right)$ plane) considered [6].

Table 2. Structural parameters for the $\mathrm{Bi}_{2} \mathrm{O}_{3}: \mathrm{Ho}^{3+}\left(1 \mathrm{~mol}\right.$ \%) films obtained at different $\mathrm{O}_{2}$ partial pressures with constant substrate temperature at $400{ }^{\circ} \mathrm{C}$.

\begin{tabular}{|c|c|c|c|c|c|}
\hline $\mathrm{O}_{2}$ Partial Pressure (mT) & Crystallite Size (D) nm & Strain $(\varepsilon) \times 10^{-4}$ & $\sigma_{\text {Stress }} \mathrm{GPa} \times 10^{-3}$ & Dislocation $(\delta) \times 10^{4}$ lines $/ \mathrm{m}^{2}$ & $\mathrm{TC}_{\mathrm{hkl}}$ \\
\hline 5 & 39.6 & 8.75 & 12.25 & 6.38 & 0.126 \\
\hline 20 & 41.0 & 8.46 & 11.84 & 5.95 & 0.069 \\
\hline 100 & 42.8 & 8.09 & 11.33 & 5.46 & 0.058 \\
\hline 200 & 44.9 & 7.77 & 10.88 & 4.96 & 0.120 \\
\hline
\end{tabular}

In Figures 1 and 2, the relative XRD peak intensities of certain crystal planes are noticeably different, indicating a variation among the growth rates of certain crystal planes [52]. The different deposition conditions (different substrate temperature and pressure) lead into the anisotropic growth of crystals, random orientation of crystal planes and different shapes and thicknesses of the thin films. Similar results were observed on the XRD patterns of indium tin oxide thin films that were grown by direct current magnetron sputtering at different $\mathrm{O}_{2}$ partial pressures [53]. Dev et al. [6] reported on the structural and optical properties of undoped and $\mathrm{B}$ doped $\mathrm{Bi}_{2} \mathrm{O}_{3}$ thin films. They observed variations in the intensities of the $(11 \overline{2})$ and $(02 \overline{2})$ diffraction peaks in the $\alpha-\mathrm{Bi}_{2} \mathrm{O}_{3}$ due to the enhancement of stacking defects in the $\mathrm{Bi}_{2} \mathrm{O}_{3}$ lattice structure, the segregation of the $\mathrm{B}$ dopant around the grain boundaries and the change of intrinsic strain through doping. Kumari et al. [18] studied Bi thin films that were deposited by thermal evaporation at varying substrate temperatures and they found that the substrate temperature strongly affected the surface morphology and crystalline orientation of the Bi thin films.

The FESEM images of the $\mathrm{Bi}_{2} \mathrm{O}_{3}: \mathrm{Ho}^{3+}$ films deposited at different temperatures $\left(\mathrm{T}_{\mathrm{S}}=\mathrm{RT}, 200,300\right.$, 400,500 and $600{ }^{\circ} \mathrm{C}$,) are reported in Figure 3a-f respectively. The images clearly indicate a change in surface morphology which is associated with an increase in substrate temperature and that the morphologeis of the thin films were strongly dependent on the deposition conditions. The images reveal non-uniform morphology without any cracks. At lower substrate temperatures (Figure 3a for $\mathrm{RT})$, the films had small grains sizes and poor crystallinity. At higher temperatures (200, 300 and $400^{\circ} \mathrm{C}$ ), the surfaces appeared rough, and agglomerated particles were distributed inhomogeneously on the substrate surface Figure $3 \mathrm{~b}-\mathrm{d}$. The aggregation of small crystalline grains was also evident under these conditions. At a substrate temperature of $500{ }^{\circ} \mathrm{C}$ (Figure 3e) the film consisted of small crystallites which were well distributed over the entire substrate area and clearly revealed a clear "step-and-terrace structure" [54,55]. At $600{ }^{\circ} \mathrm{C}$, the film showed the same "step-and-terrace structure" along with a few tetragonal bipyramidal crystals which are highlighted with red circles in Figure 4. The appearance of the tetragonal crystals at $600{ }^{\circ} \mathrm{C}$ is attributed to the dominance of the $\beta-\mathrm{Bi}_{2} \mathrm{O}_{3}$ phase, which is also confirmed by the XRD results. The $\mathrm{Bi}$ and $\mathrm{O}$ atoms contain a lot of kinetic energy when they arrive at the Si substrate surface during the deposition process. At lower substrate temperatures (RT), the atoms have low mobility and the total energy (三 kinetic energy plus thermal energy) rather supports a diffusive force which is unable to overcome the interaction or attractive force between the atoms and the substrate surface. This results in a decrease in grouping which is needed for nucleation and island formation, which ultimately leads to the growth of small grains on the substrate [56,57]. An increase in substrate temperature increases the total thermal energy of the atoms, which increases the surface diffusion of the $\mathrm{Bi}$ and $\mathrm{O}$ atoms. These atoms also do not have sufficient time to nucleate since they arrive on the surface of the substrate with high kinetic energy [58]. The collisions among the diffusing atoms are therefore greater than those between the atoms and the substrate surfaces, and tend to adhere to one another, resulting in the nucleation of tiny nanoclusters at the higher substrate temperatures $[56,58]$. At 500 and $600{ }^{\circ} \mathrm{C}$, the kinetic energy of the atoms is even higher, resulting in an increase in atom mobility and enhanced surface diffusion which ultimately results in differences in 
surface morphology [59]. Four different magnification FESEM images of the sample deposited at RT are shown in Figure 5. The irregular shape and non-uniformity of the film can clearly be observed.
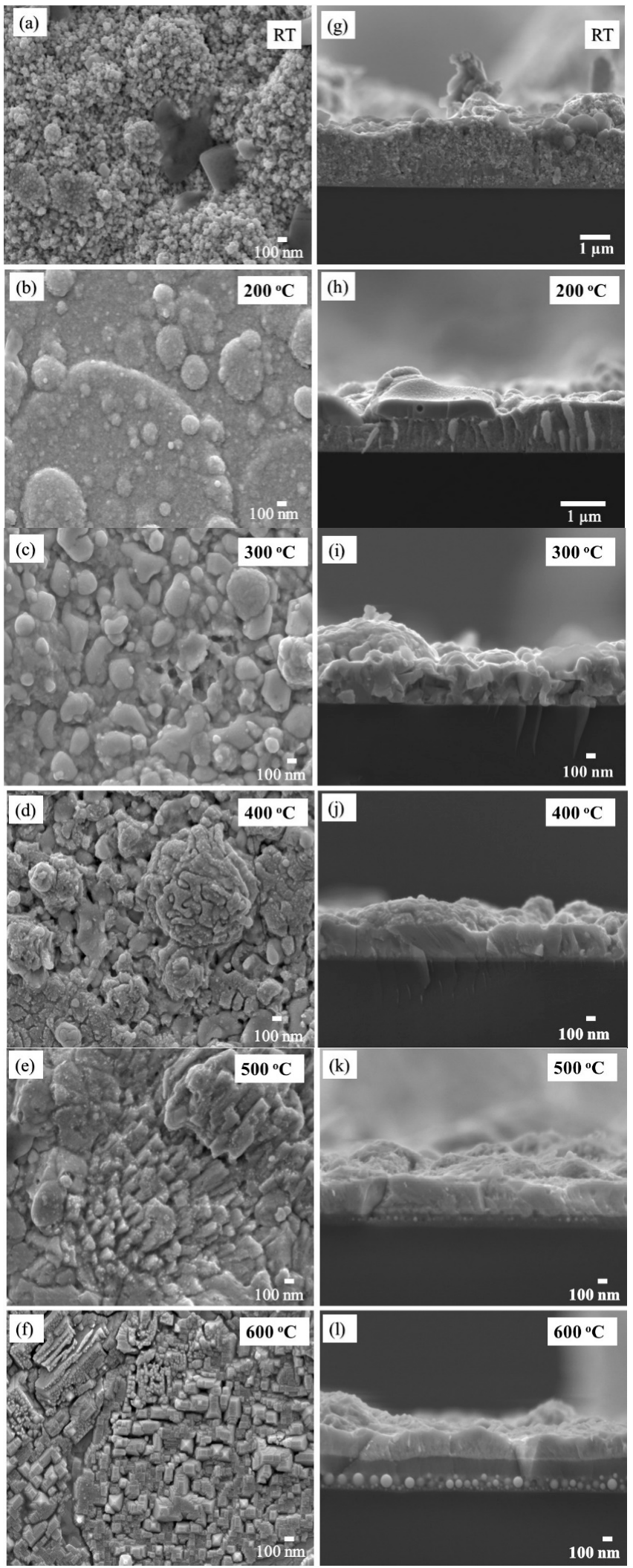

Figure 3. FESEM images (a-f) and cross-sections ( $(\mathbf{g}-\mathbf{l})$ of $\mathrm{Bi}_{2} \mathrm{O}_{3}: \mathrm{Ho}^{3+}$ thin films deposited at different substrate temperatures. 


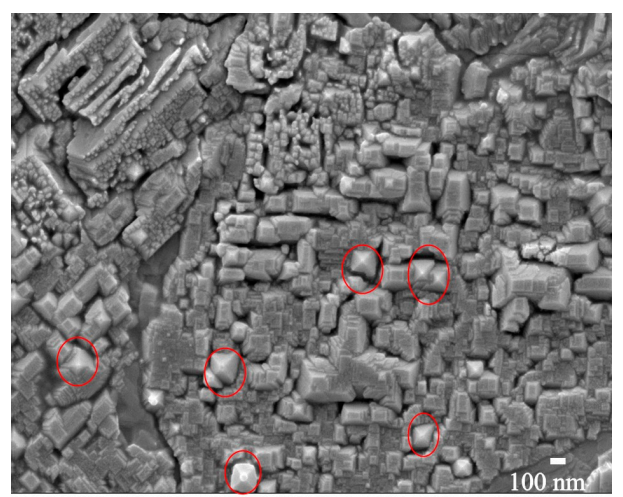

Figure 4. FESEM image of $\mathrm{Bi}_{2} \mathrm{O}_{3}: \mathrm{Ho}^{3+}$ thin film deposited with substrate temperature $600{ }^{\circ} \mathrm{C}$, and the tetragonal bipyramids are marked with red circles.
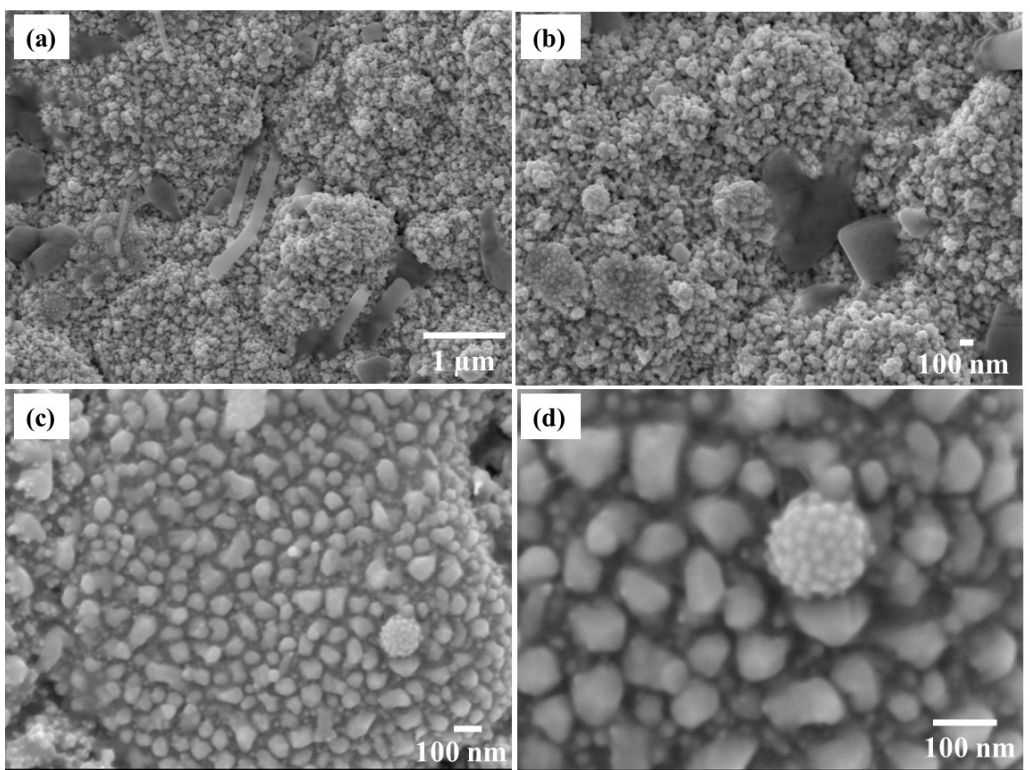

Figure 5. FESEM images of the sample deposited at RT with different magnifications (a) $\times 20,000$ (b) $\times 30,000$ (c) $\times 60,000$ (d) $\times 150,000$, as pointed out on the scale bars.

Average particle size was calculated by choosing isolated particles from the FESEM using ImageJ software (version 1.53e). Histograms of the particle size distribution pattern were fitted with Gaussian distributions to calculate average particle sizes of the $\mathrm{Bi}_{2} \mathrm{O}_{3}: \mathrm{Ho}^{3+}$ thin films deposited at different substrate temperatures. The average particle size was $50 \mathrm{~nm}$ for RT, $57 \mathrm{~nm}$ for $200{ }^{\circ} \mathrm{C}, 81 \mathrm{~nm}$ for $300{ }^{\circ} \mathrm{C}, 66 \mathrm{~nm}$ for $400{ }^{\circ} \mathrm{C}, 56 \mathrm{~nm}$ for $500{ }^{\circ} \mathrm{C}$ and $74 \mathrm{~nm}$ for $600^{\circ} \mathrm{C}$, as shown in Figure $6 \mathrm{a}-\mathrm{f}$. The average particle size increased until the substrate temperature of $300^{\circ} \mathrm{C}$ due to the effects on nucleation, crystal growth and the aggregation of small grains. The decrease in the average particle size with a further increase in the substrate temperature up to $500^{\circ} \mathrm{C}$ was due to less agglomeration of the small grains. The average particle size again increased at a higher substrate temperature $\left(\mathrm{T}_{\mathrm{S}}=600{ }^{\circ} \mathrm{C}\right)$, possibly due to the partial phase transformation to the $\beta-\mathrm{Bi}_{2} \mathrm{O}_{3}$, resulting in nucleation along the (200) plane of $\beta-\mathrm{Bi}_{2} \mathrm{O}_{3}$. The cross-section images of the $\mathrm{Bi}_{2} \mathrm{O}_{3}: \mathrm{Ho}^{3+}$ films at different substrate temperatures are given in Figure 3g-l and the average thickness of each thin film was calculated using ImageJ software. These calculations indicate a decrease in thickness as a function of temperature increase, and thickness was calculated as $1380 \pm 13,855 \pm 15,319 \pm 16,307 \pm 13,303 \pm 12$ and $218 \pm 10 \mathrm{~nm}$ for the substrate temperatures of RT, 200, 300, 400, 500 and $600{ }^{\circ} \mathrm{C}$, respectively. This may have been due to densification, crystallization and the formation of large grain sizes, as previously reported by Tay et al. [60]. Additionally, at the high substrate temperatures (500 and $600^{\circ} \mathrm{C}$ ), interdiffusion of the 
$\mathrm{Bi}, \mathrm{O}$ and $\mathrm{Si}$ may have occurred, which could have led to the formation of the spherical particles at the thin film interface, as shown in Figure $3 \mathrm{k}-\mathrm{l}$. This is supported by the higher density and larger spherical particles which were present at $600{ }^{\circ} \mathrm{C}$ (Figure 3i) compared to those obtained at $500{ }^{\circ} \mathrm{C}$.

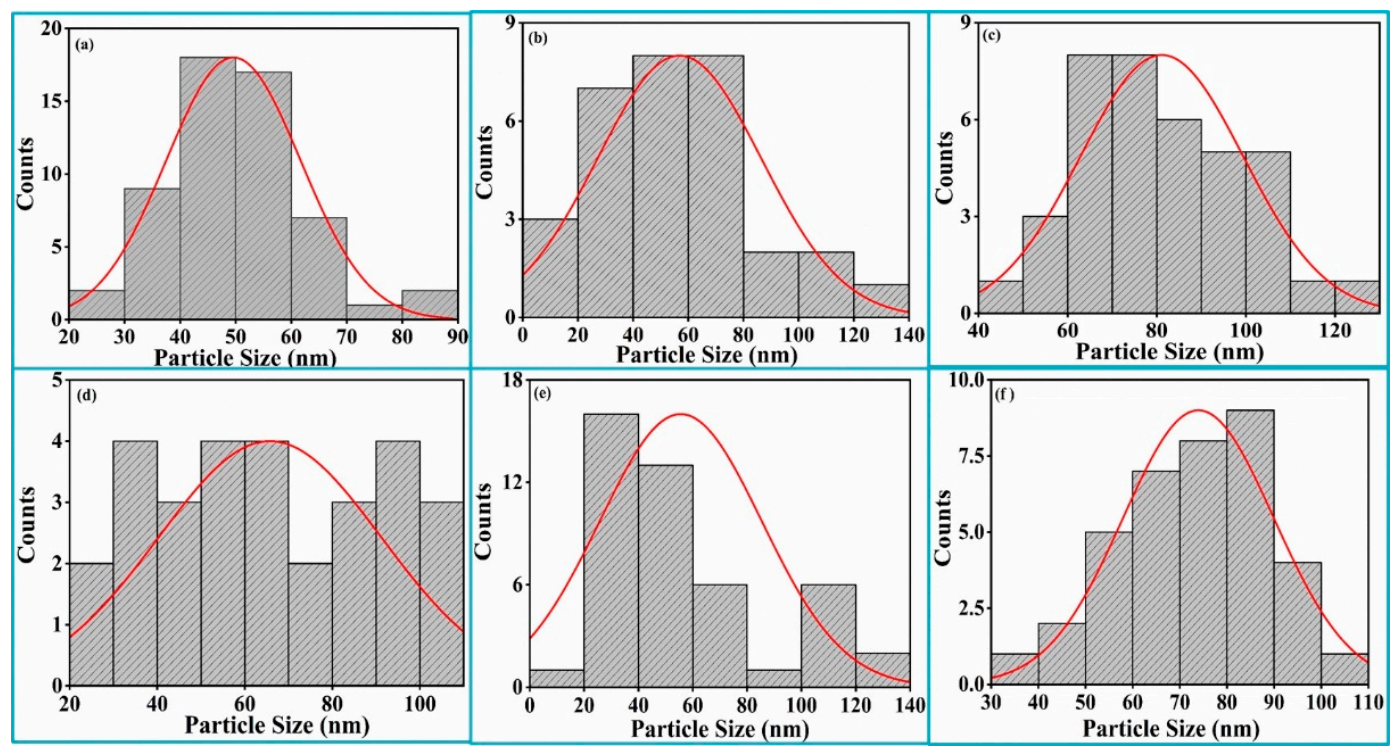

Figure 6. Histograms for particle size distribution and Gaussian fitting curves of the $\mathrm{Bi}_{2} \mathrm{O}_{3}: \mathrm{Ho}^{3+}$ thin films deposited at different substrate temperatures: (a) RT, (b) $200{ }^{\circ} \mathrm{C}$, (c) $300{ }^{\circ} \mathrm{C}$ (d) $400{ }^{\circ} \mathrm{C},(\mathbf{e}) 500{ }^{\circ} \mathrm{C}$ and (f) $600{ }^{\circ} \mathrm{C}$.

The EDS elemental analysis of the $\mathrm{Bi}_{2} \mathrm{O}_{3}: \mathrm{Ho}^{3+}(1 \mathrm{~mol}$ \%) film deposited at different substrate temperatures indicated the presence of $\mathrm{Bi}, \mathrm{O}$ and $\mathrm{Ho}$, as displayed in Figure S1 (Supplementary Materials). The results also indicate the presence of $\mathrm{Si}$, which is attributed to the substrate used, while the presence of $\mathrm{Al}$ in the EDS analysis may have originated from the sample holder used in this study. The elemental analysis clearly indicates significant changes in the wt. $\%$ of $\mathrm{Bi}, \mathrm{O}$ and $\mathrm{Ho}$ with an increase in $\mathrm{T}_{\mathrm{S}}$. At $500{ }^{\circ} \mathrm{C}$ the elemental content of the thin layer indicated wt. $\%$ of $\mathrm{Bi}$ and $\mathrm{O}$ which were close to the theoretical stoichiometry of $\mathrm{Bi}_{2} \mathrm{O}_{3}$, indicating that the product deposited at this temperature consisted of only the $\alpha-\mathrm{Bi}_{2} \mathrm{O}_{3}$ phase, which is in agreement with the XRD result.

The FESEM cross-section image of the $\mathrm{Ho}^{3+}$-doped $\mathrm{Bi}_{2} \mathrm{O}_{3}$ film from $\mathrm{T}_{\mathrm{S}}=600{ }^{\circ} \mathrm{C}$ is presented in Figure $7 \mathrm{a}$. To examine the elemental compositions in the three different regions indicated, typically selected spots 1, 2 and 3 represent the coated film surface, substrate $(\mathrm{Si})$ and the $\mathrm{Bi}_{2} \mathrm{O}_{3} / \mathrm{Si}$ interface respectively, where the EDS measurements were performed. The elemental analysis of spot 1 and spot 3 exhibited the stoichiometry of the expected $\mathrm{Bi}_{2} \mathrm{O}_{3}$ product, while the elemental analysis of spot 2 showed a maximum wt.\% Si present (as expected) as indicated in the Figure $7 \mathrm{~b}-\mathrm{d}$. The presence of a substantial amount of $\mathrm{Si}$ in the interface region at spot 3 clearly confirms that interdiffusion of the deposited material and the $\mathrm{Si}$ substrate occurred, with the subsequent formation of spherical type of particles. The FESEM image of the $\mathrm{Ho}^{3+}$-doped $\mathrm{Bi}_{2} \mathrm{O}_{3}$ film obtained at $\mathrm{T}_{\mathrm{S}}=600{ }^{\circ} \mathrm{C}$ is presented in Figure S2a. The EDS spectra of the $\mathrm{Ho}^{3+}$-doped $\mathrm{Bi}_{2} \mathrm{O}_{3}$ film with $\mathrm{T}_{\mathrm{S}}=600{ }^{\circ} \mathrm{C}$ at two distinct regions were obtained as shown in Figure S2b,c, and are represented as spot 1 and spot 2 . The EDS spectra indicate that the two different regions consist of the elements $\mathrm{Bi}, \mathrm{O}, \mathrm{Ho}$ and $\mathrm{Si}$, which confirms that both the regions have nearly the same atomic wt.\% of $\mathrm{Bi}, \mathrm{O}$ and Ho elemental composition. 


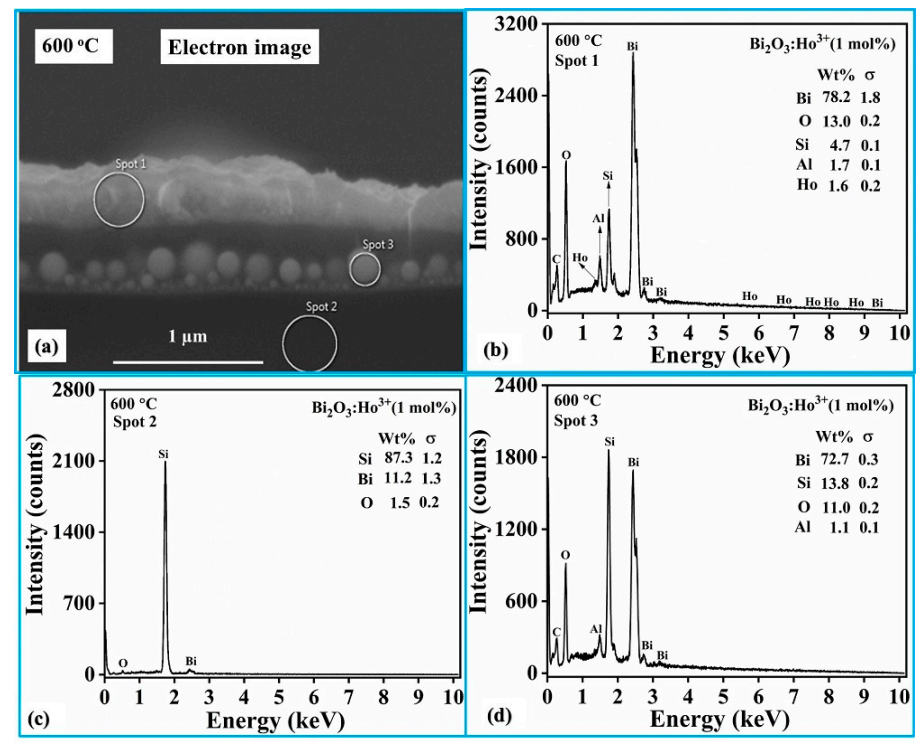

Figure 7. SEM cross-section. (a) EDS taken at spot 1 (b), spot 2 (c) and spot 3 (d) of $\mathrm{Bi}_{2} \mathrm{O}_{3}: \mathrm{Ho}^{3+}(1 \mathrm{~mol} . \%)$ deposited at $\mathrm{T}_{\mathrm{S}}=600^{\circ} \mathrm{C}$.

The subtle changes in the surface morphologies of the $\mathrm{Bi}_{2} \mathrm{O}_{3}: \mathrm{Ho}^{3+}$ PLD thin films deposited in the different oxygen partial pressures are shown in Figure 8a-d. The thin film deposited at $5 \mathrm{mT}$ in Figure $8 \mathrm{a}$ indicate uniform sized, needle-shaped grains interrupted by a few spherical shaped grains. The needle-shaped grains disappeared with an increase in oxygen pressure to $20 \mathrm{mT}$ Figure $8 \mathrm{~b}$, and only aspherical shaped grains were observed. At $100 \mathrm{mT}$ oxygen (in Figure 8c) the small spherical grains became agglomerated, resulting in the formation of larger bigger grains that were randomly distributed on the film's surface. A further oxygen pressure increase to $200 \mathrm{mT}$ resulted in the formation of finely packed and uniformly sized grains on the surface (see Figure 8d). FESEM images with two different magnifications of the film obtained at an oxygen partial pressure of $200 \mathrm{mT}$ are presented in Figure S3. The uniformity of the film is clear.
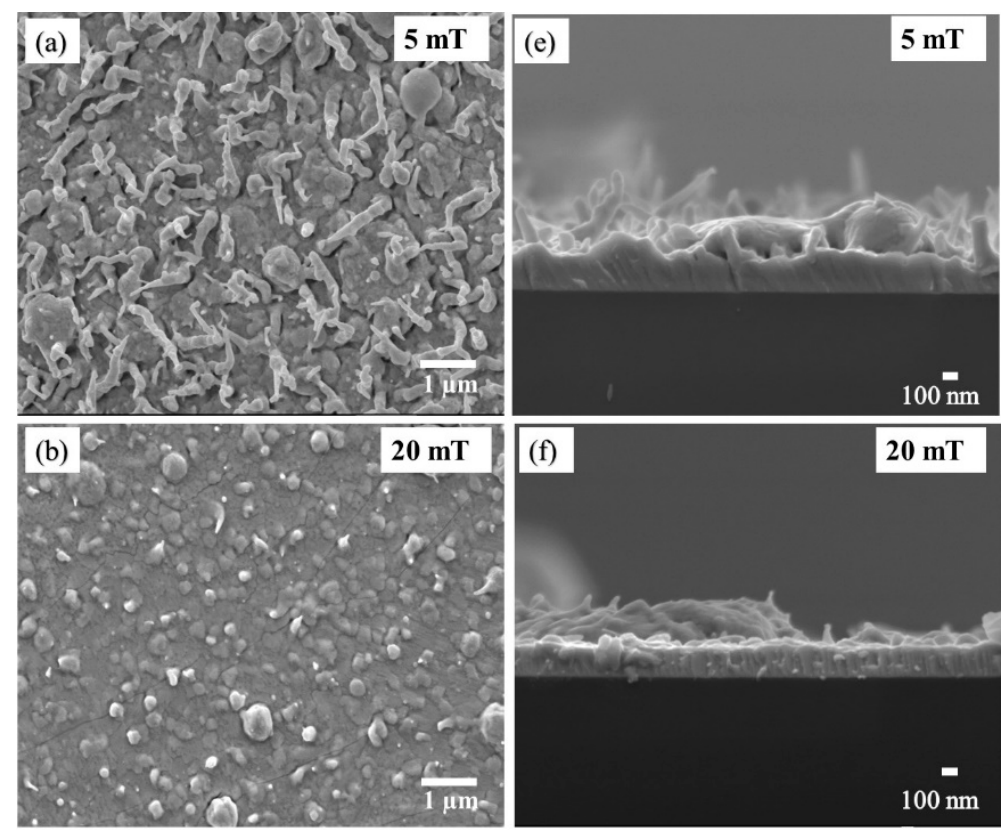

Figure 8. Cont. 

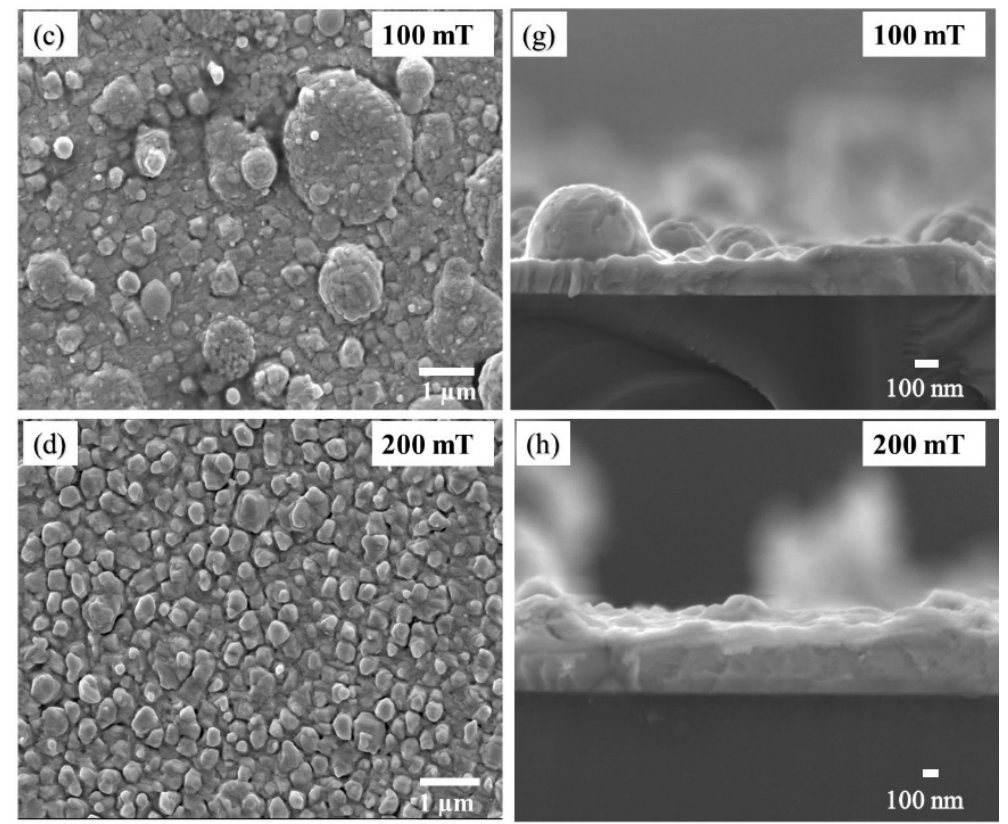

Figure 8. FESEM images (a-d) and cross-sections (e-h) of $\mathrm{Bi}_{2} \mathrm{O}_{3}: \mathrm{Ho}^{3+}$ thin films deposited in the different oxygen partial pressures.

Li et al. [61] observed similar behaviour for $\mathrm{SrBi}_{2} \mathrm{Ta}_{2} \mathrm{O}_{9}$ thin films. At low oxygen pressure (5 and $20 \mathrm{mT}$ ), the plume components avoid condensation due to the low probability of these molecules interacting with the chamber oxygen gas molecules and thus reached the substrate surface with relatively high kinetic energy to form the distinct grains observed [62]. As the oxygen pressure increased to $100 \mathrm{mT}$, the collision probability among the plume components with the chamber oxygen increased, which decreased their kinetic energy. As a result, the surface diffusion of the atoms slows down, condition which favours grain growth, resulting in a bigger grain size due to agglomeration [63]. Further increasing the oxygen partial pressure to $200 \mathrm{mT}$ increased the possibility of more frequent collisions between the atoms, decreasing the kinetic energy even more. This reduces the ability of the atoms to move on the substrate surface, which reduces the degree of agglomeration, resulting in better results at a higher temperature $[64,65]$. Ali et al. [66] also observed similar results during the deposition of thin $\mathrm{Y}_{2} \mathrm{O}_{2} \mathrm{~S}: \mathrm{Eu}^{3+}$ films using PLD. The deposition at higher oxygen partial pressure led to nucleation and growth of smaller nanoparticles with less agglomeration. The changes in the surface morphology might also be due to the orientation of the crystal [67]. The likelihood of this was observed in the XRD result reported in Figure 2. At $5 \mathrm{mT}$ pressure, the product on the substrate surface was dominated by $\alpha-\mathrm{Bi}_{2} \mathrm{O}_{3}$ in relation to the non-stochiometric $\mathrm{Bi}_{2} \mathrm{O}_{2.3}$; when the oxygen partial pressure was increased to $100 \mathrm{mT}$, the non-stochiometric $\mathrm{Bi}_{2} \mathrm{O}_{2.3}$ phase dominated; and at the highest oxygen partial pressure (200 mT), $\alpha-\mathrm{Bi}_{2} \mathrm{O}_{3}$ became the dominated phase when compared to that of the $100 \mathrm{mT}$ oxygen partial pressure. Figure 9 shows the histograms for the particle size distribution and the Gaussian fitting curves of the $\mathrm{Bi}_{2} \mathrm{O}_{3}: \mathrm{Ho}^{3+}$ thin films deposited in the different oxygen partial pressures. The average particle size was found to be $82 \mathrm{~nm}$ for $5 \mathrm{mT}, 117 \mathrm{~nm}$ for $20 \mathrm{mT}$, $153 \mathrm{~nm}$ for $100 \mathrm{mT}$ and $177 \mathrm{~nm}$ for $200 \mathrm{mT}$. It significantly increased with an increase in the oxygen partial pressure and conformed that an almost uniform particle distribution occurred at the $200 \mathrm{mT}$ oxygen pressure. 


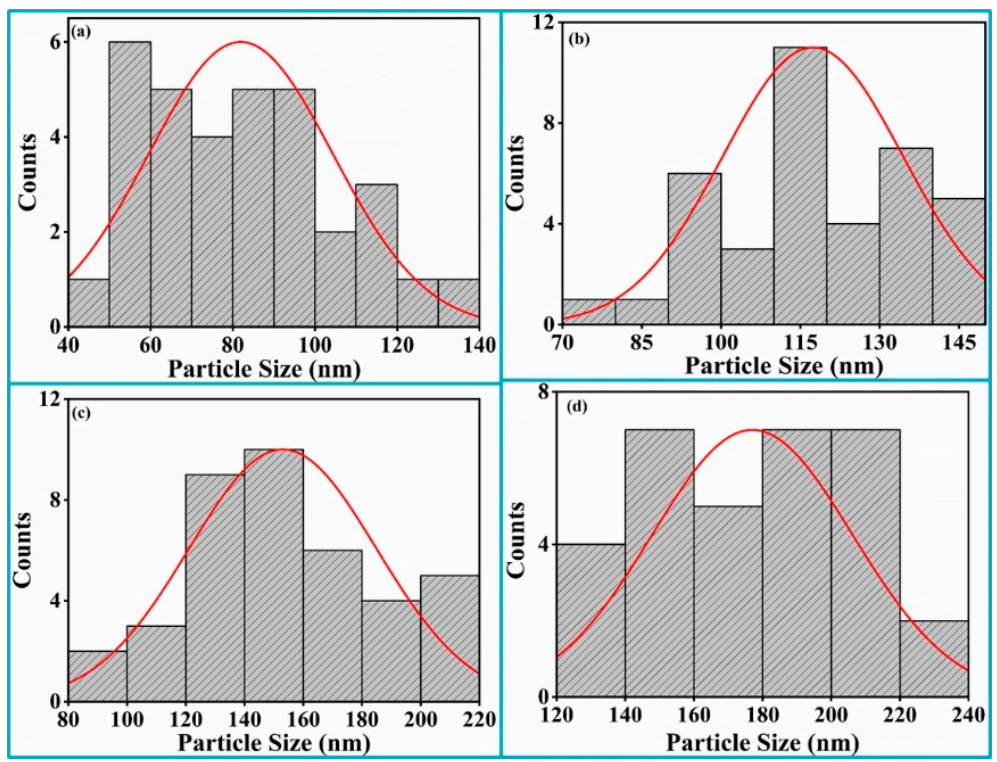

Figure 9. Histograms for particle size distribution and Gaussian fitting curves of the $\mathrm{Bi}_{2} \mathrm{O}_{3}: \mathrm{Ho}^{3+}$ thin films deposited in the different oxygen partial pressures: (a) $5 \mathrm{mT}$, (b) $20 \mathrm{mT}$ (c) $100 \mathrm{mT}$ and (d) $200 \mathrm{mT}$.

The FESEM results were also used to study the film thickness on the substrate surface. This indicated that the average film thickness remained almost constant at $226 \pm 10 \mathrm{~nm}$ when the oxygen partial pressure was varied between 5 and $20 \mathrm{mT}$. The film thickness increased to $248 \pm 37$ and $515 \pm 19 \mathrm{~nm}$ when the partial pressure was increased to 100 and $200 \mathrm{mT}$, respectively. The deposition rate was calculated to be $15 \mathrm{~nm} / \mathrm{min}$ for the 5 and $20 \mathrm{mT}$ oxygen partial pressures. Further increases in the oxygen partial pressure accelerated the film deposition rate to 16.5 and $34 \mathrm{~nm} / \mathrm{min}$ for 100 and $200 \mathrm{mT}$, respectively. The increase of the thin film thickness at higher the oxygen partial pressures is therefore attributed to the increase in the deposition rate. At low oxygen pressure, the ablated species have a high kinetic energy, and the mean free path is long and can easily reach the substrate. Some of the incident ablated species with high kinetic energy tend to desorb from the substrate due to the effect of re-sputtering. That leads to a decrease in the deposition rate. With an increase of oxygen pressure, the mean free path of the ablated species becomes shorter, which leads to an increase in collisions between the ablated species and the background oxygen molecules. As a result, they lose some of their partial kinetic energy before reaching the substrate, resulting in an increasing number of adatoms which manifests itself in an increase in deposition rate at higher oxygen pressures $[65,68]$. Zhang et al. [68] and John et al. [66] observed a similar result for the $\mathrm{Bi}_{2} \mathrm{O}_{3}-\mathrm{ZnO}-\mathrm{Nb}_{2} \mathrm{O}_{5}$ thin films and $\mathrm{BaSnO}_{3}$ thin films deposited by the PLD method. The EDS elemental analysis of the $\mathrm{Bi}_{2} \mathrm{O}_{3}: \mathrm{Ho}^{3+}(1 \mathrm{~mol} . \%)$ films deposited at different $\mathrm{O}_{2}$ partial pressures with $\mathrm{T}_{\mathrm{S}}=400{ }^{\circ} \mathrm{C}$ indicated the presence of $\mathrm{Bi}, \mathrm{O}$ and Ho elements and are reported in Figure S4.

AFM analysis is a power technique to quantitatively measure the nanometric dimensional surface roughness and for visualizing the surface nano-textures of the deposited films. The 3D-AFM images of the $\mathrm{Bi}_{2} \mathrm{O}_{3}: \mathrm{Ho}^{3+}(1 \mathrm{~mol} . \%)$ films deposited at different $\mathrm{T}_{\mathrm{S}}$ in vacuo are given in Figure $10 \mathrm{a}-\mathrm{f}$. The films exhibited agglomerate grains at low $\mathrm{T}_{\mathrm{S}}\left(\mathrm{RT}, 200,300\right.$ and $400{ }^{\circ} \mathrm{C}$ ) and decreases in agglomeration at 500 and $600{ }^{\circ} \mathrm{C}$. The plot of the surface root mean square (RMS) roughness values of the films as a function of substate temperature is shown in Figure 10g. The calculated RMS roughness value decreased with an increase in the $\mathrm{T}_{\mathrm{S}}: 131.0,124.9,73.9,50.7,32.1$ and $10.8 \mathrm{~nm}$ at RT, 200, 300, 400, 500 and $600{ }^{\circ} \mathrm{C}$, respectively. The results in Figure 10a-d indicate indistinct grain boundaries and very rough surfaces for the thin films produced. At higher $\mathrm{T}_{\mathrm{S}}$ the adatoms initiated the formation of more crystalline particles with defined boundaries, resulting in smoother film surfaces. At 500 and $600{ }^{\circ} \mathrm{C}$, however, the number of the adatoms decreased, resulting in a decrease in the RMS roughness value of the film. The reduction in the surface roughness at higher $\mathrm{T}_{\mathrm{S}}$ can be attributed to the increase in atom mobility, 
resulting in improved atom diffusion rates, resulting in atoms reaching their equilibrium positions very easily and quickly [58]. Both XRD patterns and AFM images of the as-deposited $\mathrm{Bi}_{2} \mathrm{O}_{3}$ films indicated that the substrate temperature has a significant effect on the crystallite size and the roughness of the film's surface.

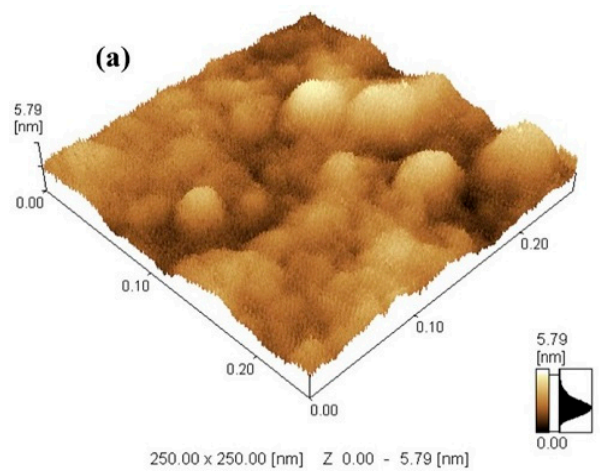

$250.00 \times 250.00[\mathrm{~nm}] \quad Z \quad 0.00-5.79[\mathrm{~nm}]$

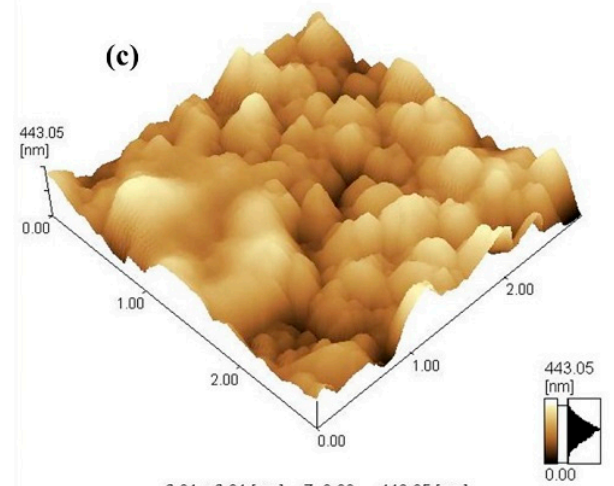

$2.81 \times 2.81$ [um] Z $0.00-443.05[\mathrm{~nm}]$

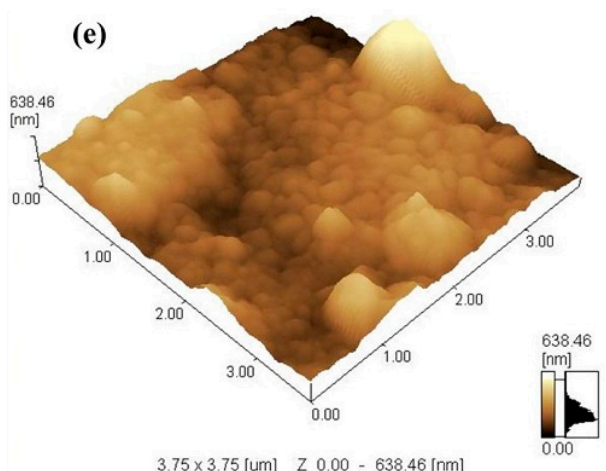

(b)

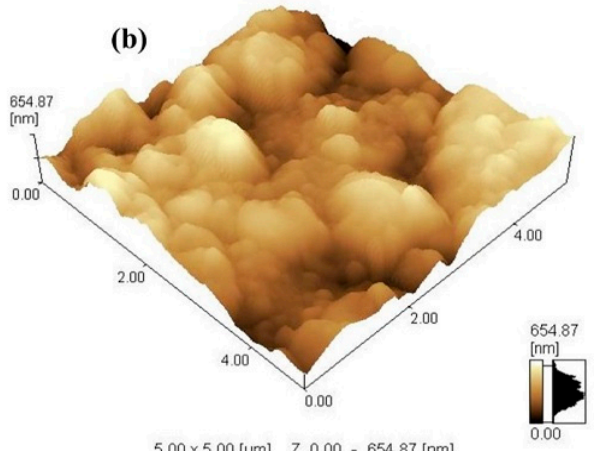

$5.00 \times 5.00[\mathrm{um}] \quad Z 0.00-654.87[\mathrm{~nm}]$
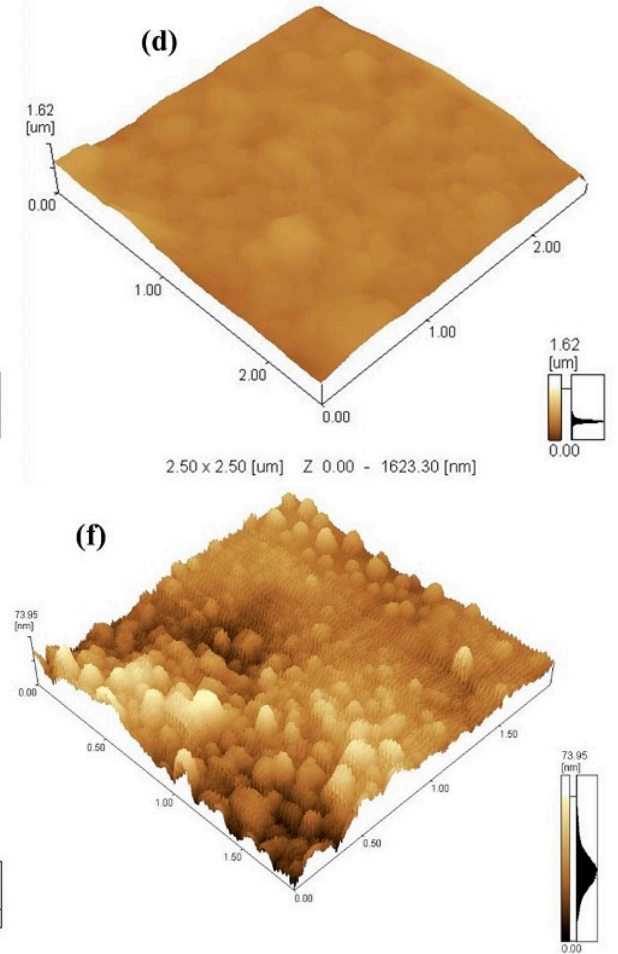

$1.87 \times 1.87[$ [um] $z 0.00 \cdot 73.95[\mathrm{~nm}]$

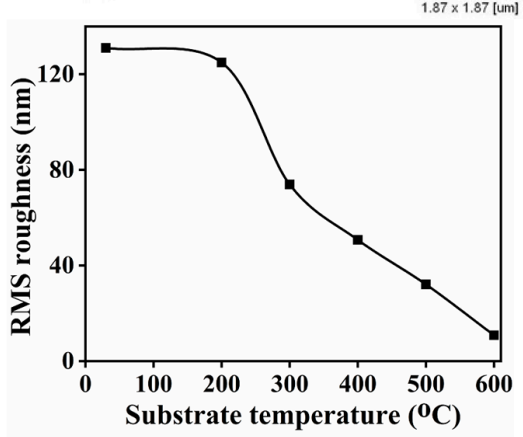

(g)

Figure 10. Three dimensional AFM images of $\mathrm{Bi}_{2} \mathrm{O}_{3}: \mathrm{Ho}^{3+}(1 \mathrm{~mol} . \%)$ films deposited in vacuo for 15 min at (a) RT, (b) $200{ }^{\circ} \mathrm{C}$, (c) $300{ }^{\circ} \mathrm{C}$, (d) $400{ }^{\circ} \mathrm{C}$, (e) $500{ }^{\circ} \mathrm{C}$ and (f) $600{ }^{\circ} \mathrm{C}$; (g) RMS roughness values of $\mathrm{Bi}_{2} \mathrm{O}_{3}: \mathrm{Ho}^{3+}(1 \mathrm{~mol} . \%)$ thin films deposited at different substrate temperatures. 
The surface morphologies of the as-deposited $\mathrm{Bi}_{2} \mathrm{O}_{3}$ thin films as a function of $\mathrm{O}_{2}$ partial pressures were also investigated by AFM analysis. The AFM images are shown in Figure 11a-d for the various $\mathrm{O}_{2}$ partial pressures. The results in Figure $11 \mathrm{~b}(20 \mathrm{mT})$ show a thin film with well-defined grain boundaries with small grains. The RMS roughness values were calculated as 105.7, 53.3, 68.3 and $114.4 \mathrm{~nm}$ at 5, 20, 100 and $200 \mathrm{mT}$, respectively. The results in Figure 11e indicate an initial decrease in the RMS roughness value with an inflection point at $20 \mathrm{mT} \mathrm{O}_{2}$ partial pressure and then a continued increase in RMS roughness with an increase in $\mathrm{O}_{2}$ partial pressure.
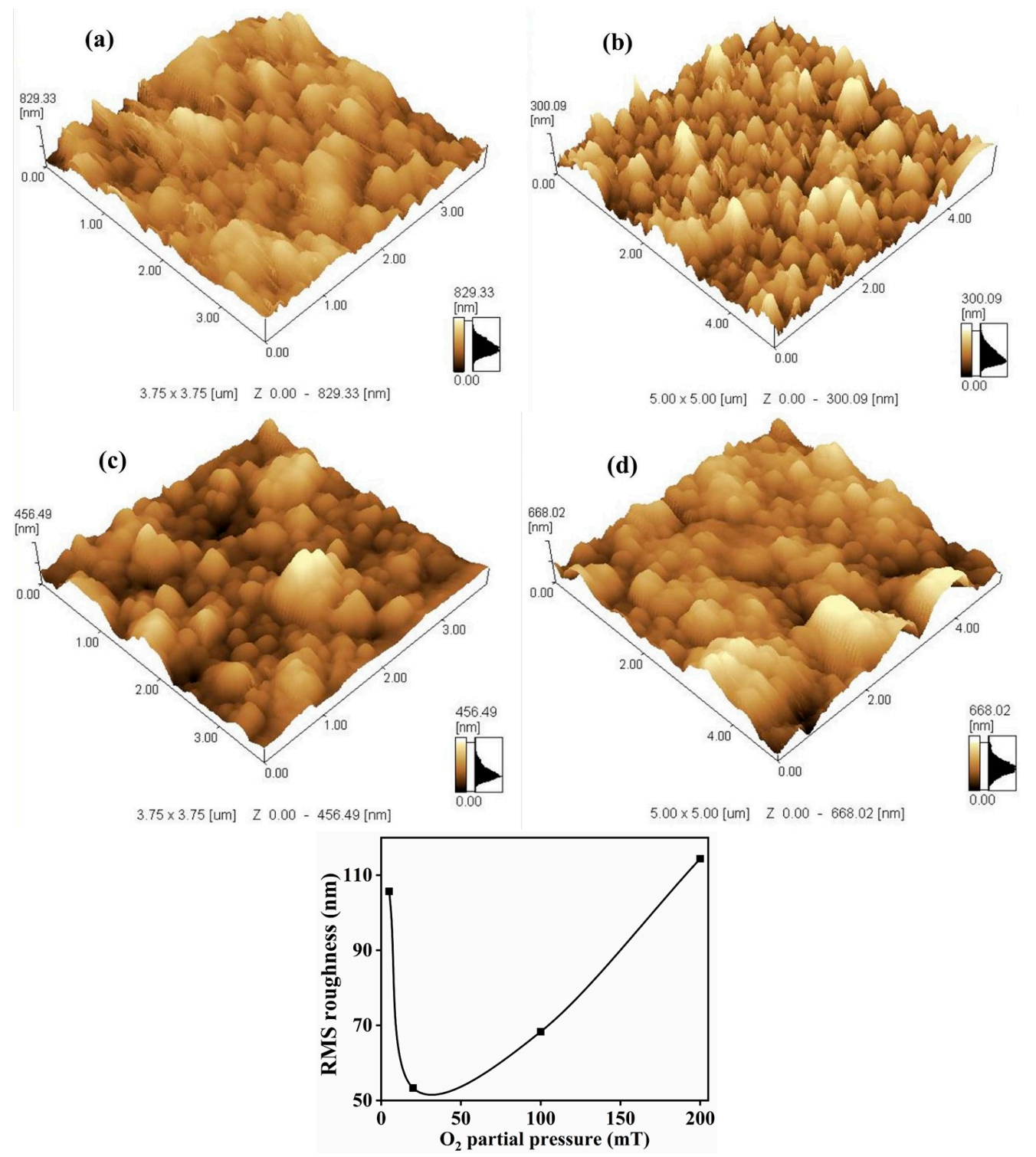

(e)

Figure 11. Three dimensional-AFM images of $\mathrm{Bi}_{2} \mathrm{O}_{3}: \mathrm{Ho}^{3+}(1 \mathrm{~mol} \%)$ film deposited in $\mathrm{O}_{2}$ partial pressures for $15 \mathrm{~min}$ at (a) $5 \mathrm{mT}$, (b) $20 \mathrm{mT}$, (c) $100 \mathrm{mT}$ and (d) $200 \mathrm{mT}$. (e) RMS roughness values of $\mathrm{Bi}_{2} \mathrm{O}_{3}: \mathrm{Ho}^{3+}(1 \mathrm{~mol} . \%)$ thin films deposited at different $\mathrm{O}_{2}$ partial pressures.

The XPS survey spectrum of a 1 mol.\% Ho-loaded $\mathrm{Bi}_{2} \mathrm{O}_{3}$ thin film obtained at a substrate temperature of $500{ }^{\circ} \mathrm{C}$ reported in Figure 12. The XPS spectrum indicates the presence of Bi (Bi 4f, Bi 4d, Bi 4p, Bi 5p and Bi 5d), oxygen (O 1s) and carbon (C 1s), as indexed in Figure 12. Interestingly, the spectrum shows no traces of Ho oxide or the metal ion, which can only be attributed to its low concentration, or maybe due to its low atomic sensitivity factor, i.e., 2.469 [69]. Survey and 
core-level XPS spectra were corrected for the charge shift using the $\mathrm{C} 1 \mathrm{~s}$ peak of adventitious carbon $(\mathrm{BE}=284.7 \mathrm{eV})$, which was used as a reference $[2,69]$.

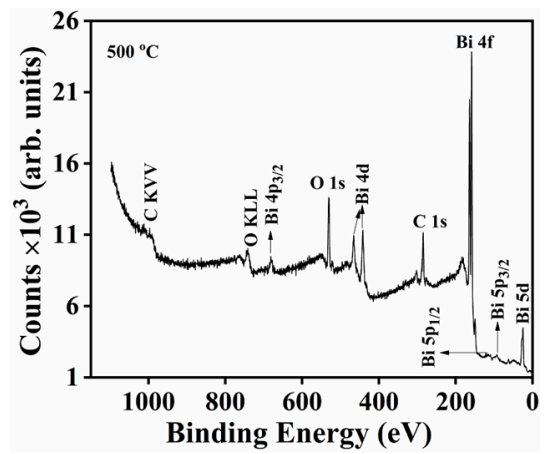

Figure 12. XPS survey spectra of $\mathrm{Bi}_{2} \mathrm{O}_{3}: \mathrm{Ho}^{3+}$ thin film at a substrate temperature of $500{ }^{\circ} \mathrm{C}$.

The high-resolution spectra of the different films obtained at the different substrate temperatures show that the Bi $4 f_{5 / 2}$ and $B i 4 f_{7 / 2}$ peaks were separated with a binding energy of $5.33 \mathrm{eV}$ and along with small peaks at the low binding energy side of each peak, as shown in Figure 13a. The binding energies of the peaks and the corresponding full-width at the half maxima of the peaks (FWHM) are tabulated in Table 3. No shoulder peaks were observed at $500{ }^{\circ} \mathrm{C}$ and the peak was symmetric in nature. The spectra of $\mathrm{Bi} 4 \mathrm{f}$ deposited on the substrate at the other temperatures, however, displayed small peaks on the lower-binding energy side of each of the larger peaks and were asymmetric in nature, suggesting that each peak consists of at least two different peaks. A similar phenomenon was observed for the $\mathrm{O} 1 \mathrm{~s}$ high resolution spectra (Figure 13b).
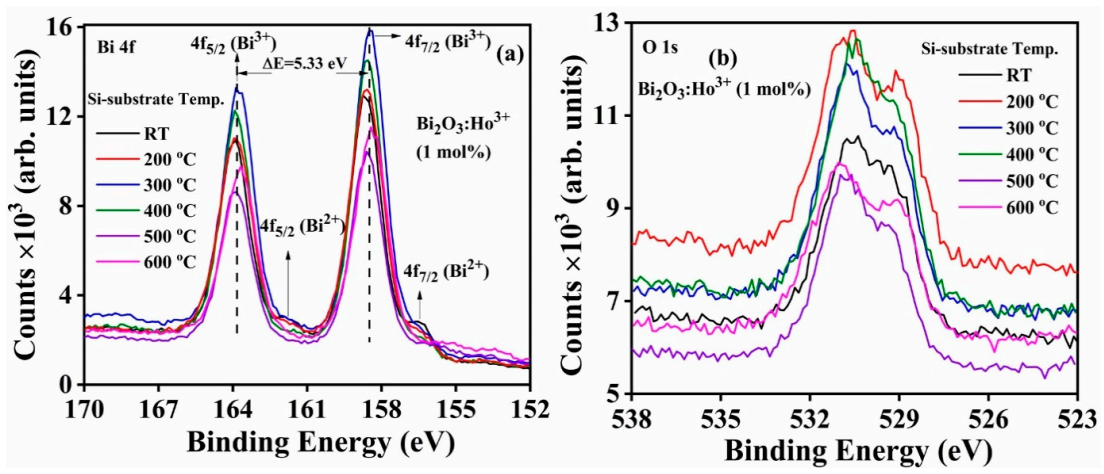

Figure 13. High-resolution XPS spectra of (a) $\mathrm{Bi} 4 \mathrm{f}$ and (b) $\mathrm{O}$ 1s for $\mathrm{Bi}_{2} \mathrm{O}_{3}: \mathrm{Ho}^{3+}$ thin films deposited at different substrate temperatures.

Table 3. Peak positions and FWHM of the 4f Bi and O 1s XPS peaks of the $\mathrm{Bi}_{2} \mathrm{O}_{3}: \mathrm{Ho}^{3+}$ thin films deposited at different substrate temperatures.

\begin{tabular}{ccccc}
\hline \multirow{2}{*}{$\mathbf{T}_{\mathbf{s}}$} & \multicolumn{2}{c}{ Bi $\mathbf{4 f}_{\mathbf{7 / 2}}$} & \multicolumn{2}{c}{ Bi O 1s } \\
\cline { 2 - 5 } & Binding Energy (eV) & FWHM & Binding Energy (eV) & FWHM \\
\hline $\mathrm{RT}$ & 158.7 & 1.38 & 530.4 & 3.22 \\
$200^{\circ} \mathrm{C}$ & 158.6 & 1.48 & 530.5 & 3.57 \\
$300^{\circ} \mathrm{C}$ & 159.5 & 1.44 & 530.8 & 3.27 \\
$400^{\circ} \mathrm{C}$ & 158.6 & 1.43 & 530.5 & 3.15 \\
$500^{\circ} \mathrm{C}$ & 158.6 & 1.38 & 530.6 & 3.07 \\
$600{ }^{\circ} \mathrm{C}$ & 158.4 & 1.68 & 531.0 & 3.74 \\
\hline
\end{tabular}

The Bi $4 \mathrm{f}$ peak in Figure 14a- $\mathrm{f}$ was deconvoluted into two separate peaks with binding energies equal to $158 \pm 0.3 \mathrm{eV}$ and $163.6 \pm 0.3 \mathrm{eV}$, respectively, and those are assigned to $\mathrm{Bi}^{3+} 4 \mathrm{f}_{7 / 2}$ and $\mathrm{Bi}^{3+} 4 \mathrm{f}_{5 / 2}$, 
respectively $[69,70]$. The shoulder peaks which appeared at the lower binding energies of $156.2 \pm 0.6$ and $161.5 \pm 0.6 \mathrm{eV}$ are assigned to the $\mathrm{Bi}^{2+} 4 \mathrm{f}_{7 / 2}$ and $\mathrm{Bi}^{2+} 4 \mathrm{f}_{5 / 2}$, respectively [71,72]. The presence of $\mathrm{Bi}$ in a lower oxidation state may be due to the presence of oxygen deficiencies within the samples [71]. The deposited film at a substrate temperature of $500{ }^{\circ} \mathrm{C}$ showed only a single oxidation state of $\mathrm{Bi}$ $\left(\mathrm{Bi}^{3+}\right)$, indicating that this sample is well defined as only $\alpha-\mathrm{Bi}_{2} \mathrm{O}_{3}$, which correlates well with the XRD results. At $600{ }^{\circ} \mathrm{C}$, there was a mixed phase product $\left(\alpha\right.$ and $\beta$ ) which was dominated by $\beta-\mathrm{Bi}_{2} \mathrm{O}_{3}$ which is also consistent with the XRD results. The results in Table 4 confirm that the $\mathrm{Bi}^{2+} / \mathrm{Bi}^{3+}$ peak ratio decreased with an increase of substrate temperature as far as $400{ }^{\circ} \mathrm{C}$ and then increased slightly at $600{ }^{\circ} \mathrm{C}$. This is proof that a well-defined $\alpha-\mathrm{Bi}_{2} \mathrm{O}_{3}$ thin film was achieved at a substrate temperature of $500^{\circ} \mathrm{C}$.
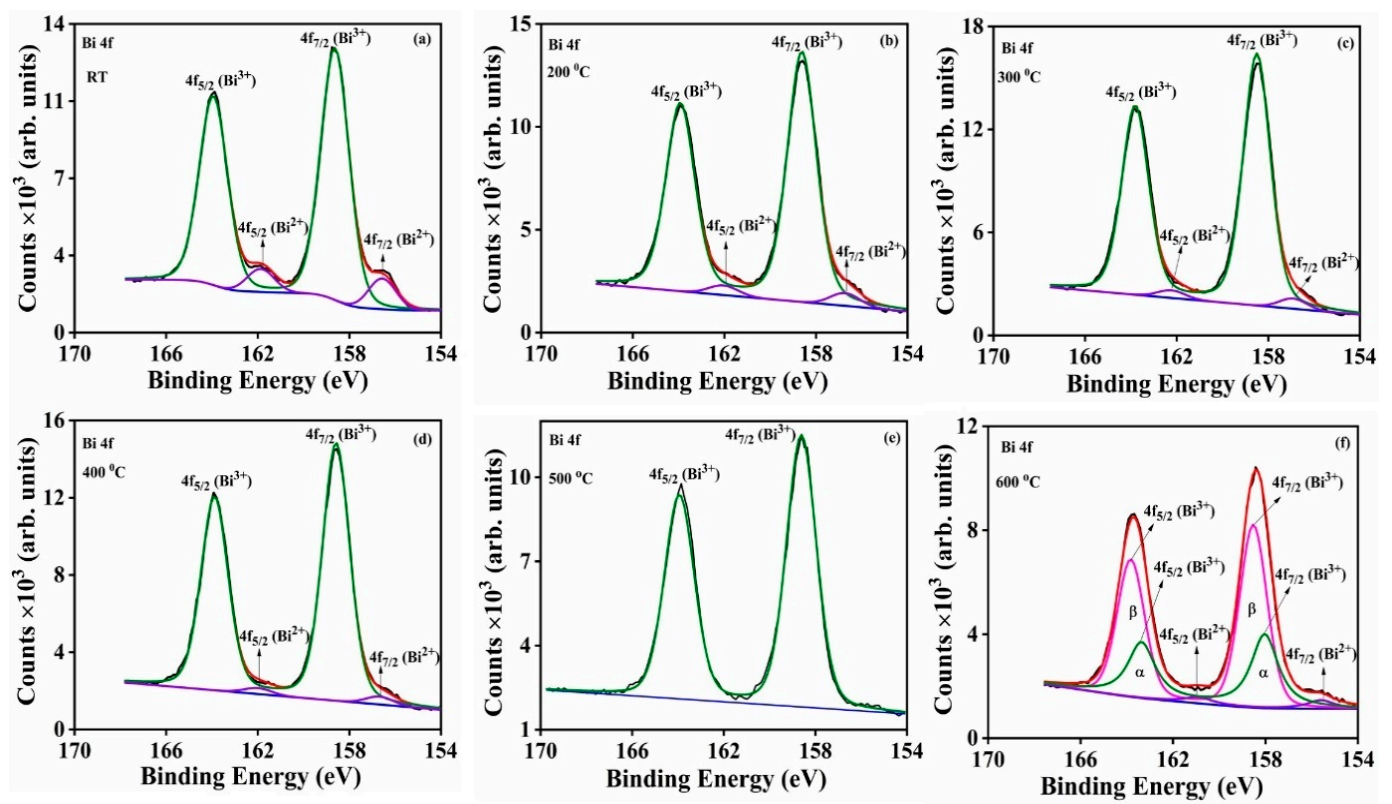

Figure 14. High-resolution XPS spectra of $\mathrm{Bi} 4 \mathrm{f}$ for $\mathrm{Bi}_{2} \mathrm{O}_{3}: \mathrm{Ho}^{3+}$ thin films deposited at different substrate temperatures: (a) RT, (b) $200{ }^{\circ} \mathrm{C}$ (c) $300{ }^{\circ} \mathrm{C}$, (d) $400{ }^{\circ} \mathrm{C}$, (e) $500{ }^{\circ} \mathrm{C}$ and (f) $600{ }^{\circ} \mathrm{C}$.

Table 4. Peak positions and areas of the $4 \mathrm{f} \mathrm{Bi} \mathrm{XPS} \mathrm{peaks} \mathrm{of} \mathrm{the} \mathrm{Bi}_{2} \mathrm{O}_{3}: \mathrm{Ho}^{3+}$ thin films deposited at different substrate temperatures.

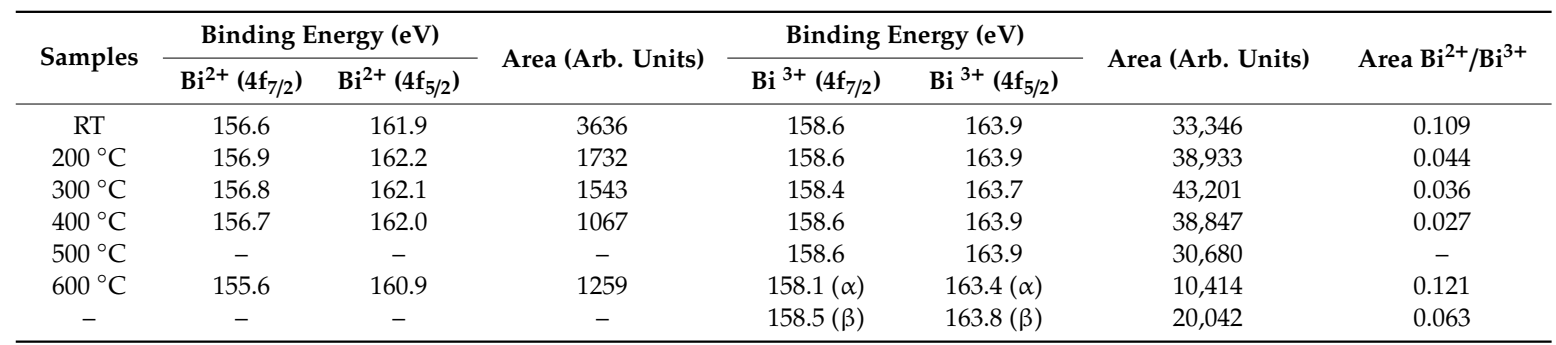

The $\mathrm{O}$ 1s spectra for the deposited $\mathrm{Bi}_{2} \mathrm{O}_{3}: \mathrm{Ho}^{3+}$ thin films, which are reported in Figure 15a-f, were fitted and the energies of the four peaks were calculated as $529.0 \pm 0.2,530.0 \pm 0.3,530.9 \pm 0.3$ and $531.7 \pm 0.4 \mathrm{eV}$ respectively. These peaks correspond to lattice oxygen $(\mathrm{Bi}-\mathrm{O})$; oxygen vacancies $\left(\mathrm{V}_{\mathrm{O}}\right)$; chemisorbed $\mathrm{H}_{2} \mathrm{O}$ or $-\mathrm{OH}$; and $\mathrm{O}-\mathrm{C}=\mathrm{O}$, respectively [2]. The $\mathrm{V}_{\mathrm{O}}$ may be due to the non-stoichiometric formation of the $\mathrm{Bi}_{2} \mathrm{O}_{3}$ (i.e., $\mathrm{Bi}_{2} \mathrm{O}_{3-x}$ ). The presence of water molecules and carbonate species were possibly due to the samples' exposure to atmospheric conditions or probably due to the absorption of these species during the product's atmospheric synthesis [2]. The $\mathrm{T}_{\mathrm{S}} 500{ }^{\circ} \mathrm{C}$ show three peaks with the absence of $\mathrm{V}_{\mathrm{O}}$, while the $\mathrm{T}_{\mathrm{S}} 600{ }^{\circ} \mathrm{C}$ showed an addition peak with binding energy at $529.5 \mathrm{eV}$, which 
is attributed to the lattice oxygen that belonged to the $\beta$-phase $[1,13]$. The calculated $\mathrm{V}_{\mathrm{O}}: \mathrm{Bi}-\mathrm{O}$ peak area's ratios decreased with increasing $\mathrm{T}_{\mathrm{S}}$ and are reported in Table 5 .
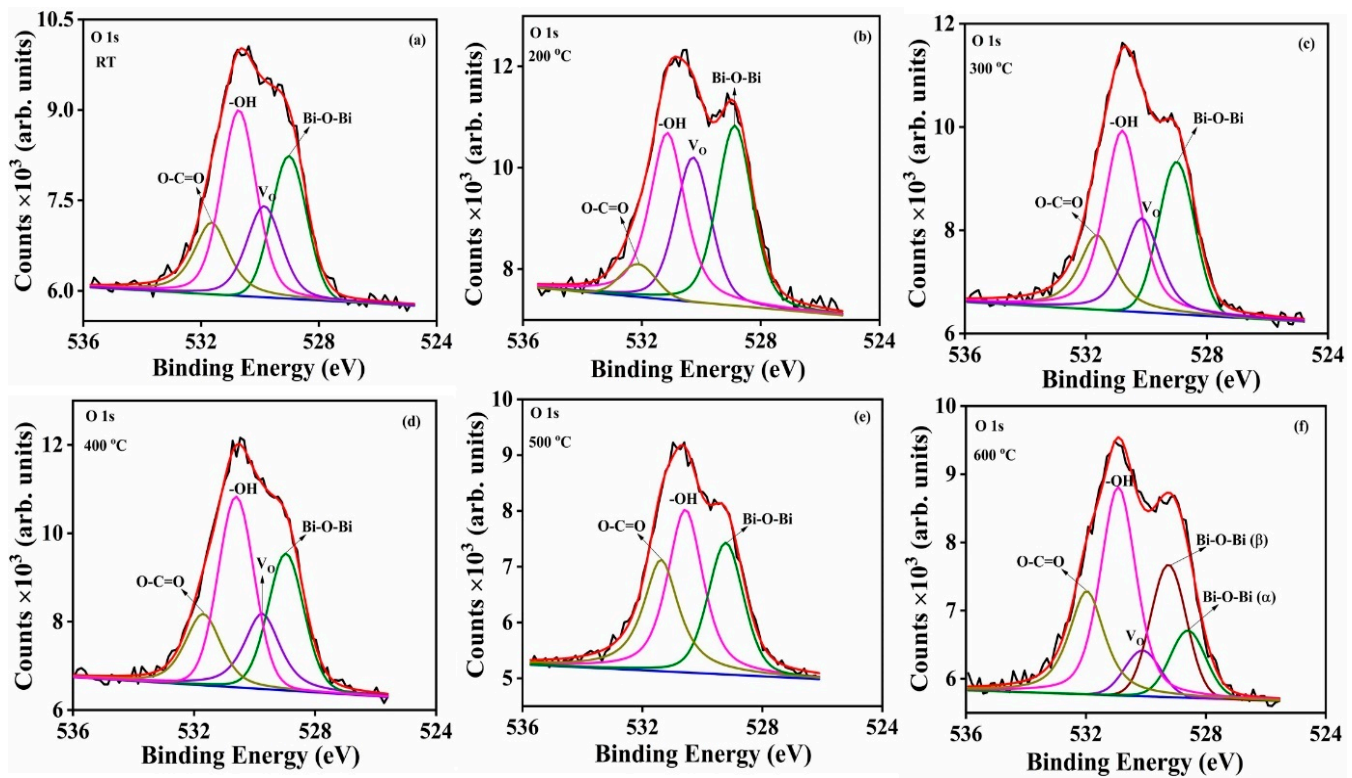

Figure 15. High-resolution XPS spectra of $\mathrm{O} 1 \mathrm{~s}$ for $\mathrm{Bi}_{2} \mathrm{O}_{3}: \mathrm{Ho}^{3+}$ thin films deposited at different substrate temperatures: (a) RT, (b) $200{ }^{\circ} \mathrm{C}$ (c) $300^{\circ} \mathrm{C}$, (d) $400{ }^{\circ} \mathrm{C}$, (e) $500{ }^{\circ} \mathrm{C}$ and (f) $600{ }^{\circ} \mathrm{C}$.

Table 5. $\mathrm{O} 1 \mathrm{~s}$ peak positions and peak areas of the $\mathrm{Bi}_{2} \mathrm{O}_{3}: \mathrm{Ho}^{3+}$ thin films deposited at different substrate temperatures.

\begin{tabular}{cccccccccc}
\hline \multirow{2}{*}{ Samples } & \multicolumn{2}{c}{$\mathbf{B i}-\mathbf{O}$} & \multicolumn{2}{c}{$\mathbf{V}_{\mathbf{O}}$} & \multicolumn{2}{c}{$-\mathbf{O H}$} & \multicolumn{2}{c}{ O-C=O } & \multirow{2}{*}{ V $_{\mathbf{O}}$ /Bi-O Area Ratio } \\
\cline { 2 - 7 } & $\mathbf{B E}(\mathbf{e V})$ & Area & $\mathbf{B E}(\mathbf{e V})$ & Area & $\mathbf{B E}(\mathbf{e V})$ & Area & $\mathbf{B E}(\mathbf{e V})$ & Area & \\
\hline $\mathrm{RT}$ & 529.0 & 3528 & 529.9 & 2631 & 530.8 & 5206 & 531.7 & 2339 & 0.746 \\
$200^{\circ} \mathrm{C}$ & 528.9 & 6106 & 530.3 & 4854 & 531.1 & 6304 & 532.1 & 965 & 0.795 \\
$300^{\circ} \mathrm{C}$ & 529.0 & 4395 & 530.1 & 3391 & 530.8 & 6448 & 531.7 & 2928 & 0.772 \\
$400^{\circ} \mathrm{C}$ & 529.0 & 4948 & 529.8 & 3332 & 530.6 & 6741 & 531.7 & 2966 & 0.673 \\
$500^{\circ} \mathrm{C}$ & 529.2 & 4037 & - & - & 530.6 & 5615 & 531.4 & 4194 & - \\
$600^{\circ} \mathrm{C}$ & $528.8(\alpha)$ & 1542 & 530.3 & 1000 & 531.1 & 5423 & 532.1 & 3008 & 0.648 \\
- & $529.5(\beta)$ & 2895 & - & - & - & - & - & - & 0.345 \\
\hline
\end{tabular}

The high-resolution spectra of $\mathrm{Bi} 4 \mathrm{f}$ and $\mathrm{O} 1 \mathrm{~s}$ as functions of different partial oxygen pressures (5, 20, 100 and $200 \mathrm{mT}$ ) are shown in Figure $16 \mathrm{a}, \mathrm{b}$. The Bi $4 \mathrm{f}_{5 / 2}$ and $\mathrm{Bi} 4 \mathrm{f}_{7 / 2}$ peaks were separated with a binding energy of $5.33 \mathrm{eV}$. The Bi $4 \mathrm{f}$ peak was fitted as two isolated peaks, and their binding energies and corresponding peak areas are summarized in Table 6 . The fitted Bi $4 \mathrm{f}$ peaks are displayed in Figure $17 \mathrm{a}-\mathrm{d}$, and the results agree with the presence of $\mathrm{Bi}$ in both of its $3+$ and $2+$ oxidation states in the product [2]. The calculated $\mathrm{Bi}^{2+}: \mathrm{Bi}^{3+}$ peak ratios increased up to an $\mathrm{O}_{2}$ partial pressure of $100 \mathrm{mT}$, and thereafter decreased with increases in the $\mathrm{O}_{2}$ partial pressure (Table 6). The $\mathrm{O} 1 \mathrm{~s} \mathrm{high}$ resolution spectra were fitted to four isolated peaks and the results are displayed in Figure 18a-d. The calculated binding energies and peaks areas are tabulated in Table 7. All four samples exhibited the non-stoichiometric nature of the deposited $\mathrm{Bi}_{2} \mathrm{O}_{3}$ product. The peak ratios of $-\mathrm{OH}: \mathrm{Bi}-\mathrm{O}-\mathrm{Bi}$ and $\mathrm{V}_{\mathrm{O}}$ : $\mathrm{Bi}-\mathrm{O}-\mathrm{Bi}$ are plotted as a function of different $\mathrm{O}_{2}$ partial pressures, which indicated the surface contamination increased till $100 \mathrm{mT}$ and was attributed to $-\mathrm{OH}$ to lattice oxygen (Bi-O-Bi) bonding and $\mathrm{V}_{\mathrm{O}}$ to lattice oxygen bonding (Bi-O-Bi) (Figure 19). 

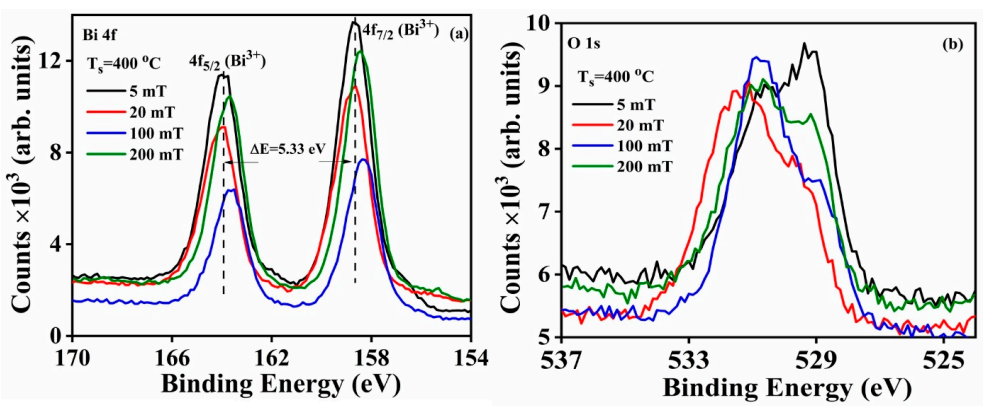

Figure 16. High-resolution XPS spectra of (a) $\mathrm{Bi} 4 \mathrm{f}$ and (b) $\mathrm{O}$ 1s for $\mathrm{Bi}_{2} \mathrm{O}_{3}: \mathrm{Ho}^{3+}$ thin films deposited at different $\mathrm{O}_{2}$ partial pressures with constant substrate temperature $\left(400{ }^{\circ} \mathrm{C}\right)$.

Table 6. Bi $4 \mathrm{f}$ peak positions and peak areas of the $\mathrm{Bi}_{2} \mathrm{O}_{3}: \mathrm{Ho}^{3+}$ thin films deposited at different $\mathrm{O}_{2}$ partial pressures $\left(\mathrm{T}_{\mathrm{S}}=400{ }^{\circ} \mathrm{C}\right)$.

\begin{tabular}{|c|c|c|c|c|c|c|c|}
\hline \multirow{2}{*}{ Samples } & \multicolumn{2}{|c|}{ Binding Energy (eV) } & \multirow{2}{*}{ Area (Arb. Units) } & \multicolumn{2}{|c|}{ Binding Energy (eV) } & \multirow{2}{*}{ Area (Arb. Units) } & \multirow{2}{*}{ Area $\mathbf{B i}^{2+} / \mathbf{B i}^{3+}$} \\
\hline & $\mathrm{Bi}^{2+}\left(4 \mathrm{f}_{7 / 2}\right)$ & $B i^{2+}\left(4 f_{5 / 2}\right)$ & & $\mathrm{Bi}^{3+}\left(4 \mathrm{f}_{7 / 2}\right)$ & $\mathrm{Bi}^{3+}\left(4 \mathrm{f}_{5 / 2}\right)$ & & \\
\hline $5 \mathrm{mT}$ & 158.2 & 163.5 & 14,953 & 158.9 & 164.2 & 26,686 & 0.560 \\
\hline $20 \mathrm{mT}$ & 158.5 & 163.6 & 16,166 & 159.0 & 164.3 & 14,071 & 1.148 \\
\hline $100 \mathrm{mT}$ & 158.1 & 163.4 & 11,630 & 158.6 & 163.9 & 10,055 & 1.157 \\
\hline $200 \mathrm{mT}$ & 158.0 & 163.3 & 11,404 & 158.6 & 163.9 & 22,322 & 0.510 \\
\hline
\end{tabular}
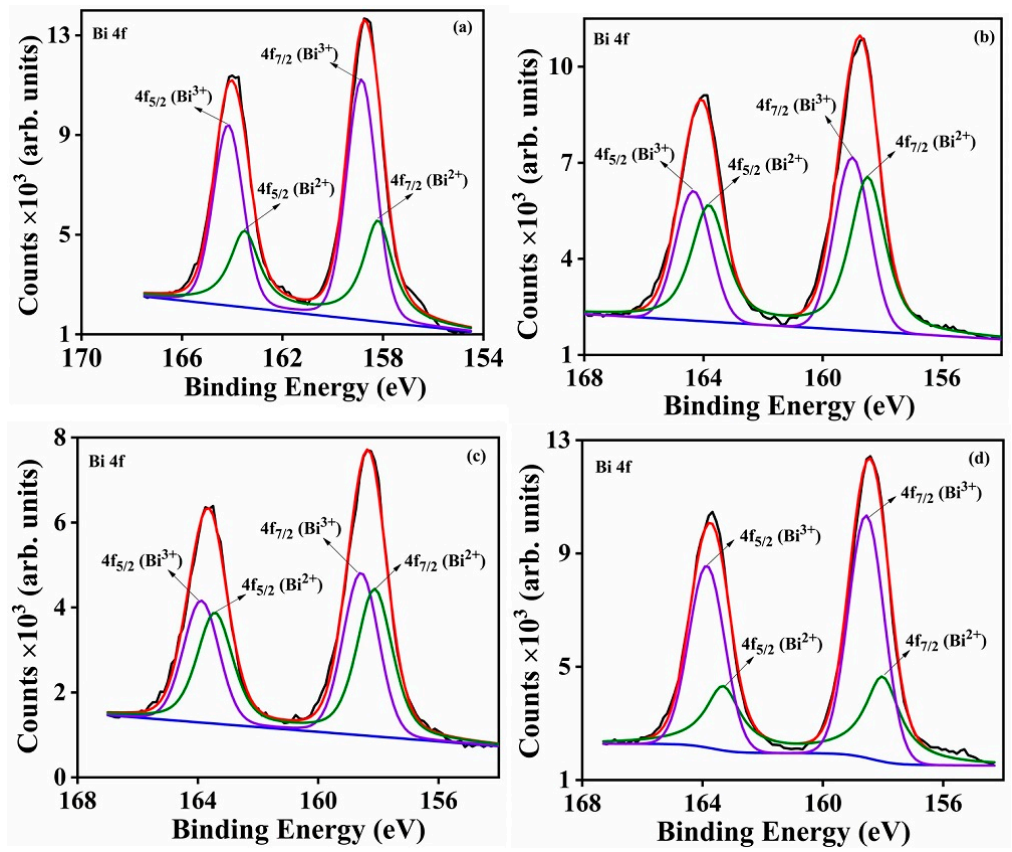

Figure 17. High-resolution XPS spectra of $\mathrm{Bi} 4 \mathrm{f}$ for $\mathrm{Bi}_{2} \mathrm{O}_{3}: \mathrm{Ho}^{3+}$ thin films deposited at different $\mathrm{O}_{2}$ partial pressures $\left(\mathrm{T}_{\mathrm{S}}=400^{\circ} \mathrm{C}\right)$ : (a) $5 \mathrm{mT}$, (b) $20 \mathrm{mT}$ (c) $100 \mathrm{mT}$ and (d) $200 \mathrm{mT}$.

Table 7. $\mathrm{O} 1 \mathrm{~s}$ peak positions and peak areas of the $\mathrm{Bi}_{2} \mathrm{O}_{3}: \mathrm{Ho}^{3+}$ thin films deposited at different $\mathrm{O}_{2}$ partial pressures $\left(\mathrm{T}_{\mathrm{S}}=400^{\circ} \mathrm{C}\right)$.

\begin{tabular}{|c|c|c|c|c|c|c|c|c|c|c|}
\hline \multirow{2}{*}{ Samples } & \multicolumn{2}{|c|}{$\mathrm{Bi}-\mathrm{O}-\mathbf{B i}$} & \multicolumn{2}{|c|}{$\mathrm{V}_{\mathrm{O}}$} & \multicolumn{2}{|c|}{$-\mathrm{OH}$} & \multicolumn{2}{|c|}{$\mathrm{O}-\mathrm{C}=\mathrm{O}$} & \multirow{2}{*}{$\begin{array}{c}\mathrm{V}_{\mathrm{O}} / \mathrm{Bi}-\mathrm{O}-\mathrm{Bi} \\
\text { Area Ratio }\end{array}$} & \multirow{2}{*}{$\begin{array}{c}-\mathrm{OH} / \mathrm{Bi}-\mathrm{O}-\mathrm{Bi} \\
\text { Area Ratio }\end{array}$} \\
\hline & BE (eV) & Area & BE (eV) & Area & BE (eV) & Area & BE (eV) & Area & & \\
\hline $5 \mathrm{mT}$ & 529.0 & 5046 & 529.9 & 2826 & 530.9 & 3637 & 532.1 & 1651 & 0.560 & 0.721 \\
\hline $20 \mathrm{mT}$ & 529.4 & 3875 & 530.8 & 4414 & 531.8 & 4292 & 532.9 & 1858 & 1.139 & 1.108 \\
\hline $100 \mathrm{mT}$ & 528.9 & 2930 & 530.1 & 4513 & 530.9 & 4748 & 531.7 & 867 & 1.540 & 1.620 \\
\hline $200 \mathrm{mT}$ & 529.0 & 4429 & 530.1 & 2174 & 531.0 & 4121 & 532.0 & 2685 & 0.491 & 0.930 \\
\hline
\end{tabular}



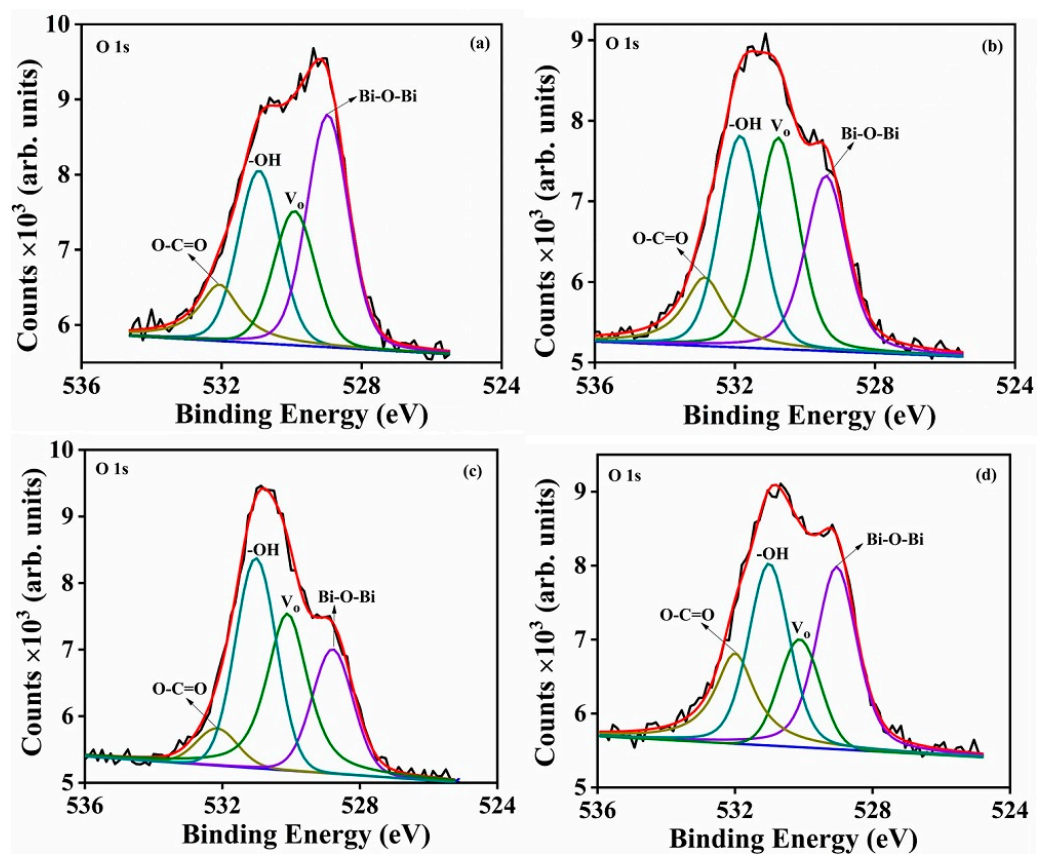

Figure 18. High-resolution XPS spectra of $\mathrm{O} 1 \mathrm{~s}$ for $\mathrm{Bi}_{2} \mathrm{O}_{3}: \mathrm{Ho}^{3+}$ thin films deposited at different $\mathrm{O}_{2}$ partial pressures $\left(\mathrm{T}_{\mathrm{S}}=400^{\circ} \mathrm{C}\right)$ : (a) $5 \mathrm{mT}$, (b) $20 \mathrm{mT}$ (c) $100 \mathrm{mT}$ and (d) $100 \mathrm{mT}$.

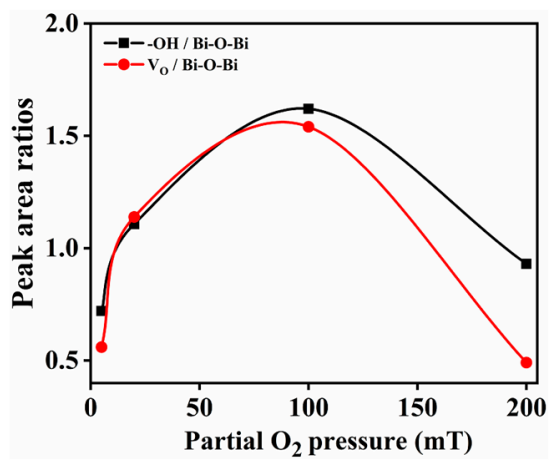

Figure 19. The variation in XPS peak area ratio with the deposition $\mathrm{O}_{2}$ partial pressures.

The diffuse reflectance characteristics of the $\mathrm{Bi}_{2} \mathrm{O}_{3}: \mathrm{Ho}^{3+}$ films deposited at different substrate temperatures are reported in Figure 20a-f. A sharp absorption peak at $406 \mathrm{~nm}$ was observed for the product isolated at RT temperature and is attributed to band edge absorption to the host. The band edge absorption shifted to the higher wavelength side (red shift) with an increases of the $\mathrm{T}_{\mathrm{S}}$ till $300^{\circ} \mathrm{C}$ (Figure 20b,c), and thereafter changed to a blue shift with a further increase of $T_{S}$ (Figure 20d-f). This temperature increase may induce the formation of localized oxygen vacancies [73] within the band gap as a result of formation of mixed $\alpha$ - and $\beta-\mathrm{Bi}_{2} \mathrm{O}_{3}$ phases. In addition, the small absorption at the $495 \mathrm{~nm}$ is assigned to the structural defects [2,74]. Figure 20 shows the diffused reflectance spectra oscillated and the lowest reflectance was due to the non-homogeneity of the films and non-uniformity particle distributions, resulting in multiple reflections from the interfaces and to their interference [11,75]. The results in Figure 20 clearly indicate that the reflectance is dependent on the film thickness, and the highest reflectance was achieved for the films grown at the RT that coincided with the thickest film observed.

The optical band gaps of thin films were estimated using the Kubelka-Munk (K-M) model [1]. The values of the direct optical bandgaps were obtained from the plots of $\left[F\left(R_{\infty}\right) h \vartheta\right]^{2}$ as a function of energy $(\mathrm{h} \vartheta)$. The direct allowed band gaps were obtained by extrapolating the linearly fitted regions of $\left[\mathrm{F}\left(\mathrm{R}_{\infty}\right) \mathrm{h} \vartheta\right]^{2}$ to zero and are shown in the inset of Figure 20a-f. These calculations indicated that 
the direct allowed bandgaps for the $\mathrm{Bi}_{2} \mathrm{O}_{3}: \mathrm{Ho}^{3+}$ thin films were $2.89,2.20,2.18,2.33,2.36$ and $2.56 \mathrm{eV}$ for $\mathrm{T}_{\mathrm{S}}$ of RT, 200, 300, 400, 500 and $600{ }^{\circ} \mathrm{C}$, respectively. These values correspond well with those reported previously [11] and with the $2.85 \mathrm{eV}$ [1] that was reported the optical band gap for a $1 \mathrm{~mol} . \%$ $\mathrm{Bi}_{2} \mathrm{O}_{3}: \mathrm{Ho}^{3+}$ powder. The obtained optical band gap values for $\mathrm{T}_{\mathrm{S}}$ of 200 to $600{ }^{\circ} \mathrm{C}$ are relatively smaller than the previous reported values for the powder sample, and that may have been due to the high density of structural defects and presence of the hetero $\alpha$ - and $\beta$-phases present in the current products.
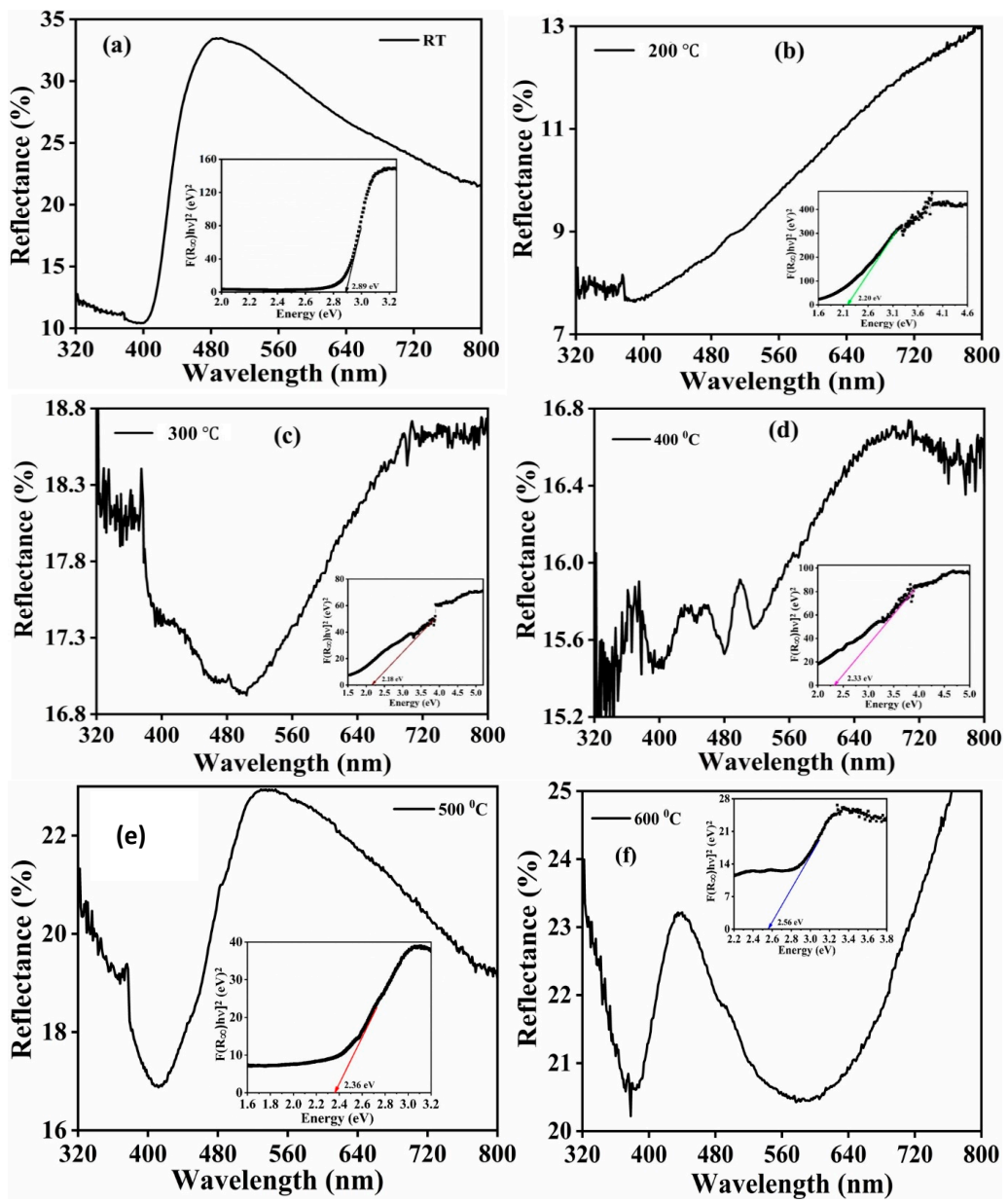

Figure 20. DR spectra of $\mathrm{Bi}_{2} \mathrm{O}_{3}: \mathrm{Ho}^{3+}$ thin films deposited at different substrate temperatures and the inset figures are represented plots of $\left(F\left(R_{\infty}\right) h \vartheta\right)^{2}$ versus photon energy.

The DR spectra of the $\mathrm{Bi}_{2} \mathrm{O}_{3}: \mathrm{Ho}^{3+}$ thin films deposited at the different $\mathrm{O}_{2}$ partial pressures are displayed in Figure 21a. The band edge absorbance appeared at approximately $390 \mathrm{~nm}$ for the $5 \mathrm{mT}$ oxygen partial pressure, and a shift was observed with an increase in the $\mathrm{O}_{2}$ partial pressure. Additionally, a small peak observed at $495 \mathrm{~nm}$ may have been due to the oxygen vacancies in the structure [1]. The bandgap value decreased up to an $\mathrm{O}_{2}$ partial pressures of $100 \mathrm{mT}$ and then increased at $200 \mathrm{mT}$ (Figure 21b). The decrease of the bandgap value was ascribed to the creation of localized states within the band gap due to an increase of the oxygen vacancies until $100 \mathrm{mT}$ [73]. The increase in the bandgap value at $200 \mathrm{mT}$ may have been due to the reduction of these oxygen vacancies. This indicates that both the $\alpha-\mathrm{Bi}_{2} \mathrm{O}_{3}$ and a suboxide $\mathrm{Bi}_{2} \mathrm{O}_{2.3}$ (oxygen deficiency) phase were formed during the $\mathrm{Bi}_{2} \mathrm{O}_{3}: \mathrm{Ho}^{3+}$ films' deposition on the Si substrates at $400{ }^{\circ} \mathrm{C}$ and in the presence of different oxygen partial pressures (5-200 $\mathrm{mT}$ ), and this is confirmed by XRD results (see Figure 2). The variations of bandgap for the thin films are well supported by XRD (Figure 2) and XPS (Figure 19) results. The reported bandgap value of stoichiometric $\alpha-\mathrm{Bi}_{2} \mathrm{O}_{3}$ was $\approx 2.85 \mathrm{eV}[1,13]$. Figure 2 showed a mixed phase of $\alpha-\mathrm{Bi}_{2} \mathrm{O}_{3}$ with a strong reflection at $27.3^{\circ}(\alpha)$ and the non-stoichiometric/ oxygen deficiency 
$\mathrm{Bi}_{2} \mathrm{O}_{2.3}$ phase with a strong reflection at $29.2^{\circ}$ (\#). The oxygen pressure increase from 5 to $100 \mathrm{mT}$ resulted in the decrease of the strong $\alpha-\mathrm{Bi}_{2} \mathrm{O}_{3} \mathrm{XRD}$ reflection at $27.3^{\circ}$, and the oxygen deficiency phase XRD peak intensity at $29.2^{\circ}$ increased, as a result of the increase of the oxygen vacancies in the film [76]. At $200 \mathrm{mT}$ the stoichiometric XRD peak intensity at $27.3^{\circ}$ increased, and the oxygen deficiency phase XRD peak intensity decreased (see Figure 2) due to the backfilled oxygen atoms occupying the oxygen vacancies, hence a reduction in the oxygen vacancies [77]. The obtained bandgap values are consistent with previously reported results [11].
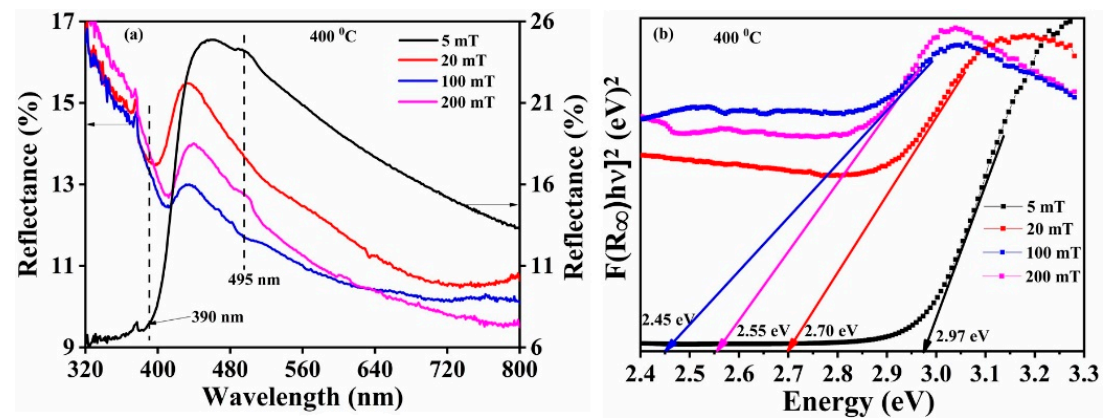

Figure 21. (a) DR spectra and (b) plots of $\left(\mathrm{F}\left(\mathrm{R}_{\infty}\right) \mathrm{h} \vartheta\right)^{2}$ versus photon energy of $\mathrm{Bi}_{2} \mathrm{O}_{3}: \mathrm{Ho}^{3+}$ thin films deposited at different $\mathrm{O}_{2}$ partial pressures $\left(\mathrm{T}_{\mathrm{S}}=400^{\circ} \mathrm{C}\right)$.

The PL excitation spectra of the isolated $\mathrm{Bi}_{2} \mathrm{O}_{3}: \mathrm{Ho}^{3+}$ thin films deposited at the different substrate temperatures were obtained at $\lambda_{\mathrm{em}}=548 \mathrm{~nm}$ and are displayed in Figure 22a. The obtained PL indicated intensity maxima at $360,419,450,466,473$, and $485 \mathrm{~nm}$ and are attributed to the ${ }^{5} \mathrm{I}_{8} \rightarrow{ }^{3} \mathrm{H}_{5},{ }^{3} \mathrm{H}_{6}$, ${ }^{5} \mathrm{I}_{8} \rightarrow{ }^{5} \mathrm{G}_{5},{ }^{5} \mathrm{I}_{8} \rightarrow{ }^{5} \mathrm{G}_{6},{ }^{5} \mathrm{~F}_{1},{ }^{5} \mathrm{I}_{8} \rightarrow{ }^{3} \mathrm{~K}_{8},{ }^{5} \mathrm{I}_{8} \rightarrow{ }^{5} \mathrm{~F}_{2}$ and ${ }^{5} \mathrm{I}_{8} \rightarrow{ }^{5} \mathrm{~F}_{3}$ transitions of $\mathrm{Ho}^{3+}$ ion. The peak at $450 \mathrm{~nm}$ appeared to be the strongest excitation peak and corresponds well to previously obtained results [1,78]. The ${ }^{5} \mathrm{I}_{8} \rightarrow{ }^{5} \mathrm{G}_{6},{ }^{5} \mathrm{~F}_{1}$ excitation peak has two peak maxima at 450 and $454 \mathrm{~nm}$. The second peak at 454 $\mathrm{nm}$ became more prominent with an increase of the substrate temperature to $600{ }^{\circ} \mathrm{C}$ compared to the peak at $450 \mathrm{~nm}$ It might be due to the $\alpha-\mathrm{Bi}_{2} \mathrm{O}_{3}$ oriented crystallographic planes that were reduced at the substrate temperature of $500{ }^{\circ} \mathrm{C}$ and partially transformed into the $\beta-\mathrm{Bi}_{2} \mathrm{O}_{3}$ phase with a further increase of the substrate temperature to $600^{\circ} \mathrm{C}$, and as a result the oriented crystallographic planes were changed, which is consistent with the XRD results (see Figure 1). Zhang et al. [79] studied the optical absorption spectra of $\mathrm{MgWO}_{4}: \mathrm{Ho}^{3+}$ crystal for light polarizations $\mathrm{E} \| \mathrm{a}, \mathrm{b}, \mathrm{c}$, where $\mathrm{a}, \mathrm{b}, \mathrm{c}$ are the orientations in the crystallographic frame $\{a, b, c\}$. The main absorption peak at about $448 \mathrm{~nm}$ due to the ${ }^{5} \mathrm{I}_{8} \rightarrow{ }^{5} \mathrm{G}_{6},{ }^{5} \mathrm{~F}_{1}$ transition of $\mathrm{Ho}^{3+}$ consisted of two peaks at about 448 and $452 \mathrm{~nm}$ due to the stark splitting [21]. When the light polarization was $\mathrm{E} \| \mathrm{c}$, the $\approx 452 \mathrm{~nm}$ peak intensity was dominant. For light polarizations $E \| \mathrm{a}$ and $\mathrm{E} \| \mathrm{b}$, the $448 \mathrm{~nm}$ peak intensity was dominant. The PL emission spectra of all the films deposited at different substrate temperatures and excited at $450 \mathrm{~nm}$ are reported Figure 22b. A broad and highly intense green emission peak was found at $548 \mathrm{~nm}$, and is ascribed to the ${ }^{5} \mathrm{~F}_{4} /{ }^{5} \mathrm{~S}_{2} \rightarrow$ ${ }^{5} \mathrm{I}_{8} \mathrm{Ho}^{3+}$ transition; the relatively weak red emission peaks at 655 and $756 \mathrm{~nm}$ are attributed to the ${ }^{5} \mathrm{~F}_{5}$ $\rightarrow{ }^{5} \mathrm{I}_{8}$ and ${ }^{5} \mathrm{~S}_{2} \rightarrow{ }^{5} \mathrm{I}_{7}$ transitions of $\mathrm{Ho}^{3+}$ ion [1]. The variations in the ratio of the emission intensities between the green and red transitions of the $\mathrm{Ho}^{3+}$ ions may be due to the phonon energy effects. It is well known that $\mathrm{Ho}^{3+}$ has several meta-stable states which are situated between its ${ }^{5} \mathrm{~F}_{5},{ }^{5} \mathrm{I}_{4},{ }^{5} \mathrm{I}_{5}$ and ${ }^{5} \mathrm{I}_{8}$ energy levels, and small energy gaps between these state give rise to the cross-relaxation effects which can lead to a high phonon energy effect. This phonon energy will diminish the intensity of the emitted red light, and the weak red intensity emission, compared to the green emission intensity, is well documented [80]. The intensity of the green emission increased with an increase in substrate temperature from RT to $500^{\circ} \mathrm{C}$ (see Figure 22c) possibly due to improved crystallinity and the formation of the stoichiometric $\alpha-\mathrm{Bi}_{2} \mathrm{O}_{3}$ product. These results correlated well with those obtained from the XRD and XPS studies. These results indicate that the surface morphology changed, and the RMS results indicated a decrease in surface roughness attributed to the increase of the substrate temperature, which 
ultimately improved the PL properties. The structural defects and oxygen vacancies also played vital roles in the PL intensity and emission profiles, and these defects acted as luminescence quenchers and/or enhancers [81]. In the present study the oxygen vacancies acted as a $\mathrm{Ho}^{3+}$ emission quencher, and the PL intensity increased with the reduction of the oxygen vacancies, which was confirmed from the XPS results. In addition, the maximum PL excitation intensity appeared at $454 \mathrm{~nm}$ with an increase in the substrate temperature to $600{ }^{\circ} \mathrm{C}$. The emission maxima with excitation at $450 \mathrm{~nm}$, therefore, appeared lower than those at $500{ }^{\circ} \mathrm{C}$, possibly due to the fact that the emission intensity was measured at a slightly lower value. The broad excitation observed in the $360-420 \mathrm{~nm}$ region for the substrate temperature $600{ }^{\circ} \mathrm{C}$ indicated the presence of crystal defects, lattice disorders that also contributed the $\mathrm{Ho}^{3+}$ excitation peaks, which was also evident in the XRD, surface morphology and XPS results. A similar result was observed for the $\mathrm{MgWO}_{4}: \mathrm{Ho}^{3+}$ crystal [79].
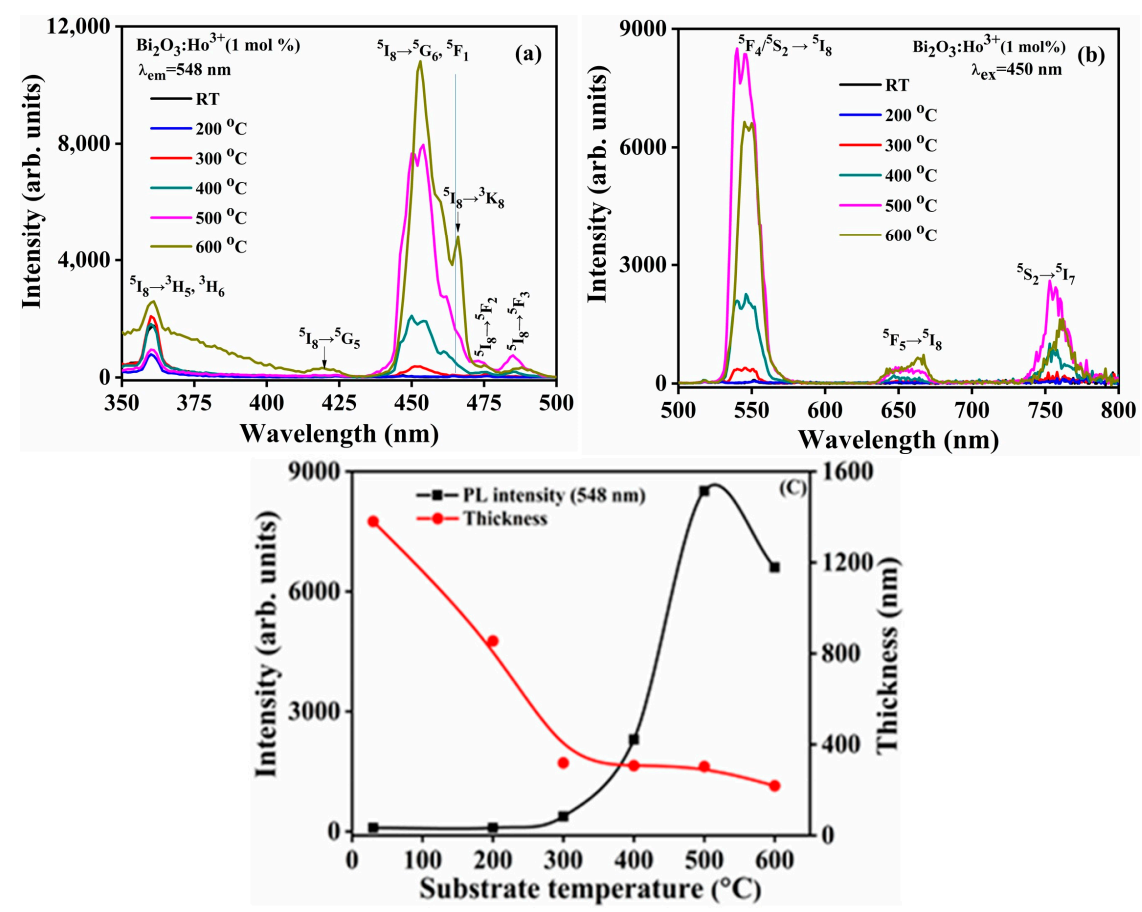

Figure 22. PL spectra of $\mathrm{Bi}_{2} \mathrm{O}_{3}: \mathrm{Ho}^{3+}$ films: (a) excitation and (b) emission spectra of the films deposited in vacuo at the substrate temperatures of RT, 200, 300, 400, 500 and $600{ }^{\circ} \mathrm{C}$. (c) The variations in PL emission intensity of the $548 \mathrm{~nm}$ peaks and the corresponding film thicknesses for the different substrate temperatures.

The excitation and emission spectra of the $\mathrm{Bi}_{2} \mathrm{O}_{3}: \mathrm{Ho}^{3+}$ thin films were studied using the films deposited at constant substrate temperature $\left(\mathrm{T}_{\mathrm{S}}=400{ }^{\circ} \mathrm{C}\right)$ and at various oxygen partial pressures, and the resultant spectra are reported in Figure 23a,b. It is clear from the results in Figure 23 that the PL excitation and emission spectra were very similar to those of the films obtained at the lower substrate temperatures $\left(<500{ }^{\circ} \mathrm{C}\right.$ (Figure 22a,b). The results indicate PL intensities were higher for the films deposited at the different oxygen partial pressures (see Figure 23c), compared to the films created in vacuo, and may be attributed to a decrease in the agglomeration of the particles. The results indicate an initial decrease in intensity with the increase of oxygen partial pressures (5-100 $\mathrm{mT}$ ), since it depends on the surface morphology of the substrate. At $5 \mathrm{mT}$ (uniform), needle-shaped grains were observed, but the increase of the oxygen partial pressure led to the agglomeration of particles, which ultimately led to a decrease of the PL intensity. At $200 \mathrm{mT}$ the PL intensity increased, possibly due to the uniform distribution and reduction of the agglomeration of the particles on the film surface. That was also confirmed by the formation of fewer oxygen vacancies and surface contamination in the form of $-\mathrm{OH}$, as indicated by the higher PL intensities. The obtained PL results are well consistent 
with the XRD and XPS results. The decrease in PL intensities in the $\mathrm{Ho}^{3+}$ transitions in the $\mathrm{Bi}_{2} \mathrm{O}_{3}$ thin films is attributed to the presence of oxygen vacancies and - $\mathrm{OH}$ groups. In the present study, the PL intensity of the $\mathrm{Bi}_{2} \mathrm{O}_{3}: \mathrm{Ho}^{3+}$ films deposited at the different substrate temperatures in vacuo and different oxygen partial pressures significantly changed with the film thickness, and the obtained results are given in Figures 22c and 23c. Figure 22c indicates that the PL intensity of the $548 \mathrm{~nm}$ peak increased with a decrease of the film thickness up to the substrate temperature of $500{ }^{\circ} \mathrm{C}$, and thereafter the PL intensity decreased at the substrate temperature of $600{ }^{\circ} \mathrm{C}$. This is the opposite of what was expected: that a thinner layer would give a lower intensity. Other secondary effects, such as the changes in crystal structure and crystallite orientation, therefore, played more pronounced roles in the increase of the intensity. An increase of the PL intensity at the higher substrate temperature was due to the formation of the mixed $\alpha-\beta \mathrm{Bi}_{2} \mathrm{O}_{3}$ phase with the dominated $\beta-\mathrm{Bi}_{2} \mathrm{O}_{3}$ phase. Additionally, the value of the texture coefficient in the (121) plane of the $\alpha-\mathrm{Bi}_{2} \mathrm{O}_{3}$ was a minimum (see Table 1 ). In Figure 23c, the PL emission intensity of the $548 \mathrm{~nm}$ peak increased with increases of film thickness and with increases in the $\mathrm{O}_{2}$ partial pressure. The increase of the PL intensity at $200 \mathrm{mT}$ was due to the uniform distribution of the particles, which was well consistent with the texture coefficient in the (121) plane of the $\alpha-\mathrm{Bi}_{2} \mathrm{O}_{3}$ (see Table 2).

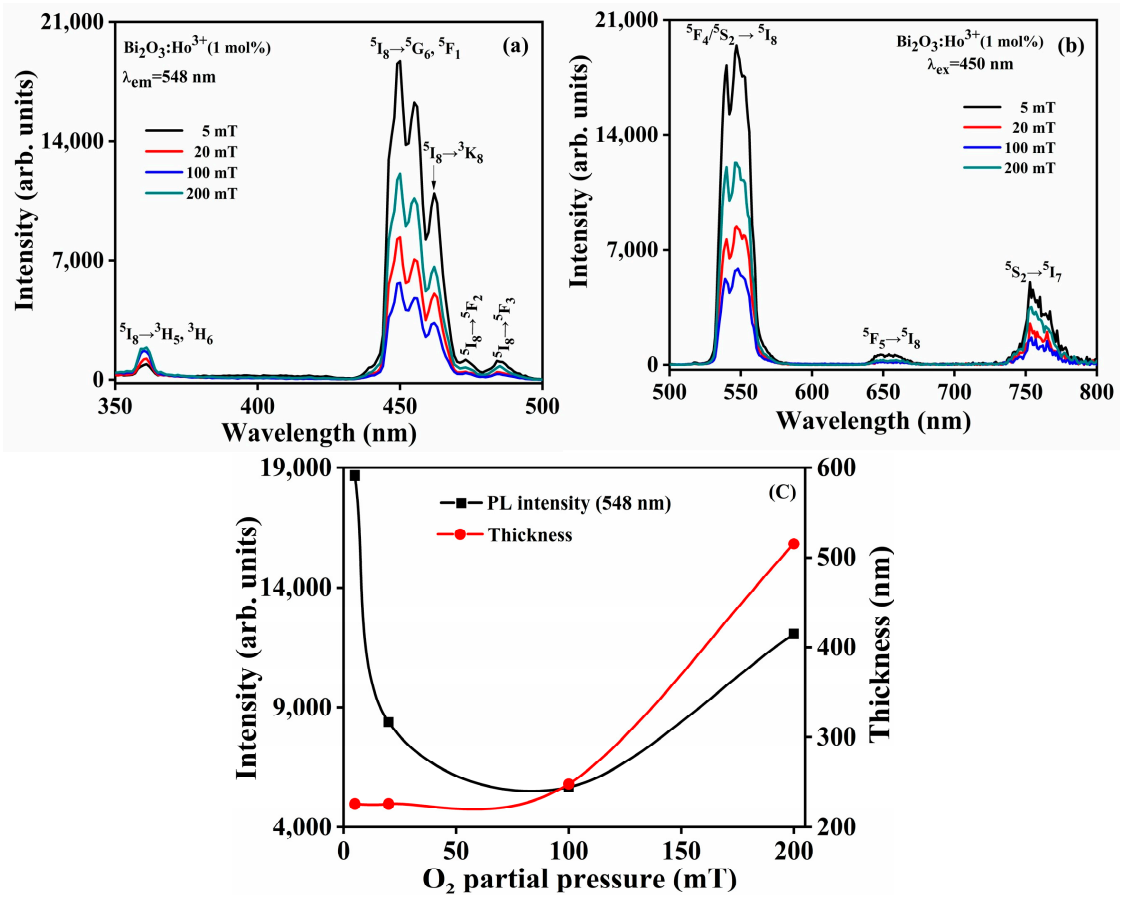

Figure 23. PL spectra of the $\mathrm{Bi}_{2} \mathrm{O}_{3}: \mathrm{Ho}^{3+}$ films: (a) excitation and (b) emission spectra of the films deposited at oxygen partial pressures of 5, 20, 100 and $200 \mathrm{mT}$ at a substrate temperature of $400{ }^{\circ} \mathrm{C}$. (c) The variation in PL emission intensity of the $548 \mathrm{~nm}$ peaks and the corresponding thickness for the different $\mathrm{O}_{2}$ partial pressure.

\section{Conclusions}

Holmium-doped $\mathrm{Bi}_{2} \mathrm{O}_{3}$ thin films were successfully deposited on $\mathrm{Si}(100)$ substrates using the PLD technique. The films were deposited at different substrate temperatures in vacuo at different oxygen partial pressures. The XRD showed that the crystallinity of the films increased with substrate temperatures, with the highest degree of crystallinity being obtained at $400{ }^{\circ} \mathrm{C}$. The XRD confirmed a single $\alpha-\mathrm{Bi}_{2} \mathrm{O}_{3}$ phase at substrate temperatures of 400 and $500{ }^{\circ} \mathrm{C}$, whereas with the substrate temperature of $600{ }^{\circ} \mathrm{C}$, there was a mixed phase of $\alpha$ - and $\beta-\mathrm{Bi}_{2} \mathrm{O}_{3}$. The XPS results showed that a close to stoichiometric $\alpha-\mathrm{Bi}_{2} \mathrm{O}_{3}: \mathrm{Ho}^{3+}$ film was synthesized at a substrate temperature of $500{ }^{\circ} \mathrm{C}$ in vacuo. Interdiffusion between the $\mathrm{Si}$ substrate and the deposited material was observed at substrate 
temperatures of $\mathrm{T}_{\mathrm{S}}=500$ and $600{ }^{\circ} \mathrm{C}$. The optical band gap of the $\mathrm{Bi}_{2} \mathrm{O}_{3}: \mathrm{Ho}^{3+}$ thin films varied from 2.89 to $2.18 \mathrm{eV}$ for the films deposited at different substrate temperatures, whereas the band gap varied between 2.97 and $2.47 \mathrm{eV}$ for the different oxygen partial pressures. The thicknesses of the films varied between 218 and $1380 \mathrm{~nm}$ and 226 to $515 \mathrm{~nm}$ for different substrate temperatures and $\mathrm{O}_{2}$ partial pressures. The photoluminescence emission increased with an increase in the substrate temperature. Furthermore, the films deposited in an $\mathrm{O}_{2}$ atmosphere gave much higher emission intensities than those deposited in vacuo at different substrate temperatures. Emission peaks associated with $\mathrm{f}-\mathrm{f}$ electronic transition for $\mathrm{Ho}^{3+}$ were observed at 548, 655, and $756 \mathrm{~nm}$.

Supplementary Materials: The following are available online at http://www.mdpi.com/2079-6412/10/12/1168/s1, Figure S1: EDS of Bi2O3: $\mathrm{Ho}^{3+}(1 \mathrm{~mol} . \%)$ deposited at different substrate temperatures (RT- $600{ }^{\circ} \mathrm{C}$ ) in vacuum, Figure S2: FESEM image (a) EDS taken at spot 1 (b) and spot 2 (c) of $\mathrm{Bi}_{2} \mathrm{O}_{3}: \mathrm{Ho}^{3+}(1 \mathrm{~mol} . \%)$ deposited at $\mathrm{T}_{\mathrm{S}}=600{ }^{\circ} \mathrm{C}$, Figure S3: FESEM images of the sample deposited with $\mathrm{O}_{2}$ partial pressure of $200 \mathrm{mT}\left(\mathrm{T}_{S}=400{ }^{\circ} \mathrm{C}\right)$ with different magnifications as indicated by the scale bars in (a) and (b) of the $\mathrm{Bi}_{2} \mathrm{O}_{3}: \mathrm{Ho}^{3+}$ thin film, Figure S4: EDS of Bi2O3:Ho3 ${ }^{+}(1 \mathrm{~mol} . \%)$ deposited at different $\mathrm{O}_{2}$ partial pressure $(5-200 \mathrm{mT})$ with $\mathrm{T}_{\mathrm{S}}=400{ }^{\circ} \mathrm{C}$.

Author Contributions: Conceptualization, D.J. and H.C.S.; methodology, D.J. and H.C.S.; formal analysis, D.J.; investigation, D.J., S.N.J., and W.D.R.; resources, H.C.S.; data curation, D.J.; writing-original draft preparation, D.J. and S.N.J.; writing-review and editing, W.P. and H.C.S.; supervision, W.P. and H.C.S.; project administration, H.C.S.; funding acquisition, H.C.S. All authors have read and agreed to the published version of the manuscript.

Funding: This research was funded by the South African Research Chairs Initiative of the Department of Science and Technology and the National Research Foundation of South Africa, grant number 84415, and the University of the Free State, South Africa.

Conflicts of Interest: The authors declare no conflict of interest.

\section{References}

1. Divya, J.; Shivaramu, N.J.; Coetsee, E.; Kroon, R.E.; Purcell, W.; Swart, H.C. Enhanced luminescence and photocatalytic activity of $\mathrm{Bi}_{2} \mathrm{O}_{3}: \mathrm{Ho}^{3+}$ needles. J. Alloys Compd. 2020, 842, 155641. [CrossRef]

2. Divya, J.; Shivaramu, N.J.; Purcell, W.; Roos, W.D.; Swart, H.C. Multifunction applications of $\mathrm{Bi}_{2} \mathrm{O}_{3}: \mathrm{Eu}^{3+}$ nanophosphor for red light emission and photocatalytic activity. Appl. Surf. Sci. 2019, 497, 143748. [CrossRef]

3. Shinde, P.V.; Shinde, N.M.; Shaikh, S.F.; Lee, D.; Yun, J.M.; Woo, L.J.; Al-Enizi, A.M.; Mane, R.S.; Kim, K.H. Room-temperature synthesis and $\mathrm{CO}_{2}$-gas sensitivity of bismuth oxide nanosensors. RSC Adv. 2020, 10, 17217-17227. [CrossRef]

4. Wang, Y.; Jiang, L.; Tang, D.; Liu, F.; Lai, Y. Characterization of porous bismuth oxide $\left(\mathrm{Bi}_{2} \mathrm{O}_{3}\right)$ nanoplates prepared by chemical bath deposition and post annealing. RSC Adv. 2015, 5, 65591-65594. [CrossRef]

5. Hasegawa, T.; Nagashima, T.; Sugimoto, N. Z-scan study of third-order optical nonlinearities in bismuth-based glasses. Opt. Commun. 2005, 250, 411-415. [CrossRef]

6. Dev, B.C.; Babu, M.H.; Podder, J.; Sagadevan, S.; Zubair, A. Low temperature synthesis of $\alpha$ - and $\beta$-phase $\mathrm{Bi}_{2} \mathrm{O}_{3}$ thin film via $\mathrm{B}$ doping: Tailoring optical band gap and $\mathrm{n}$ - to $\mathrm{p}$-type $\mathrm{Bi}_{2} \mathrm{O}_{3}$. J. Mater. Sci. Mater. Electron. 2019, 30, 15670-15682. [CrossRef]

7. Ho, C.-H.; Chan, C.-H.; Huang, Y.-S.; Tien, L.-C.; Chao, L.-C. The study of optical band edge property of bismuth oxide nanowires $\alpha-\mathrm{Bi}_{2} \mathrm{O}_{3}$. Opt. Express. 2013, 21, 11965-11972. [CrossRef]

8. Yang, X.; Lian, X.; Liu, S.; Wang, G.; Jiang, C.; Tian, J.; Chen, J.; Wang, R. Enhanced photocatalytic performance: A $\beta-\mathrm{Bi}_{2} \mathrm{O}_{3}$ thin film by nanoporous surface. J. Phys. D. Appl. Phys. 2013, 46, 1-6. [CrossRef]

9. Hasabeldaim, E.H.H.; Ntwaeaborwa, O.M.; Kroon, R.E.; Coetsee, E.; Swart, H.C. Luminescence properties of Eu doped ZnO PLD thin films: The effect of oxygen partial pressure. Superlattices Microstruct. 2020, 139, 106432. [CrossRef]

10. Sanna, S.; Esposito, V.; Graves, C.; Hjelm, J.; Andreasen, J.W.; Pryds, N. Structural instability and electrical properties in epitaxial $\mathrm{Er}_{2} \mathrm{O}_{3}$-stabilized $\mathrm{Bi}_{2} \mathrm{O}_{3}$ thin films. Solid State Ion. 2014, 266, 13-18. [CrossRef]

11. Condurache-Bota, S.; Tigau, N.; Constantinescu, C. Effect of substrate temperature on bismuth oxide thin films grown by pulsed laser deposition. SN Appl. Sci. 2020, 2, 1-10. [CrossRef]

12. Ahila, M.; Padiyan, D.P. Photoluminescence and photocatalytic properties of $\mathrm{Bi}_{2} \mathrm{O}_{3}$ nanostructures. Nano Hybrids Compos. 2017, 17, 166-170. [CrossRef] 
13. Divya, J.; Shivaramu, N.J.; Purcell, W.; Roos, W.D.; Swart, H.C. Effect of annealing temperature on the crystal structure, optical and photocatalytic properties of $\mathrm{Bi}_{2} \mathrm{O}_{3}$ needles. Appl. Surf. Sci. 2020, 520. [CrossRef]

14. Schmidt, S.; Kubaski, E.T.; Li, M.S.; Bezzon, V.D.N.; Sequinel, T.; Tebcherani, S.M. Blue or red photoluminescence emission in $\alpha-\mathrm{Bi}_{2} \mathrm{O}_{3}$ needles: Effect of synthesis method. Luminescence 2018, 33, 1281-1287. [CrossRef] [PubMed]

15. Li, C.; O'Halloran, K.P.; Ma, H.; Shi, L. Multifunctional multilayer films containing polyoxometalates and bismuth oxide nanoparticles. J. Phys. Chem. B 2009, 113, 8043-8048. [CrossRef] [PubMed]

16. Blasse, G.; Zhiran, H. The luminescence of yttria stabilized zirconia doped with $\mathrm{Bi}_{2} \mathrm{O}_{3}$. Mater. Res. Bull. 1984, 19, 1057-1062. [CrossRef]

17. Kumari, L.; Lin, J.H.; Ma, Y.R. Synthesis of bismuth oxide nanostructures by an oxidative metal vapour phase deposition technique. Nanotechnology 2007, 18, 295605. [CrossRef]

18. Kumari, L.; Lin, J.H.; Ma, Y.R. Laser oxidation and wide-band photoluminescence of thermal evaporated bismuth thin films. J. Phys. D Appl. Phys. 2008, 41, 025405. [CrossRef]

19. Schmidt, S.; Kubaski, E.T.; Volanti, D.P.; Sequinel, T.; Bezzon, V.D.N.; Beltrán, A.; Tebcherani, S.M.; Varela, J.A. Effect of Pressure-assisted heat treatment on photoluminescence emission of $\alpha-\mathrm{Bi}_{2} \mathrm{O}_{3}$ needles. Inorg. Chem. 2015, 54, 10184-10191. [CrossRef]

20. Dutta, D.P.; Roy, M.; Tyagi, A.K. Dual function of rare earth doped nano $\mathrm{Bi}_{2} \mathrm{O}_{3}$ : White light emission and photocatalytic properties. Dalt. Trans. 2012, 41, 10238-10248. [CrossRef]

21. Carnall, W.T.; Fields, P.R.; Rajnak, K. Electronic energy levels in the trivalent lanthanide aquo ions. $\mathrm{Pr}^{3+}$, $\mathrm{Nd}^{3+}, \mathrm{Pm}^{3+}, \mathrm{Sm}^{3+}, \mathrm{Dy}^{3+}, \mathrm{Ho}^{3+}, \mathrm{Er}^{3+}$, and $\mathrm{Tm}^{3+}$. J. Chem. Phys. 1968, 49, 4424-4442. [CrossRef]

22. Kaminskii, A.A. Crystalline Lasers; CRC Press: Boca Raton, FL, USA, 1996.

23. Premkumar, H.B.; Ravikumar, B.S.; Sunitha, D.V.; Nagabhushana, H.; Sharma, S.C.; Savitha, M.B.; Mohandas Bhat, S.; Nagabhushana, B.M.; Chakradhar, R.P.S. Investigation of structural and luminescence properties of $\mathrm{Ho}^{3+}$ doped $\mathrm{YAlO}_{3}$ nanophosphors synthesized through solution combustion route. Spectrochim. Acta Part A Mol. Biomol. Spectrosc. 2013, 115, 234-243. [CrossRef] [PubMed]

24. Deren, P.J.; Krupa, J.C. Spectroscopic properties of $\mathrm{LaAlO}_{3}$ doped with $\mathrm{Ho}^{3+}$. J. Alloys Compd. 2004, 380, 362-367. [CrossRef]

25. Singh, V.; Naidu, D.T.; Chakradhar, R.P.S.; Ratnakaram, Y.C.; Zhu, J.J.; Soni, M. Synthesis, characterization and optical properties of $\mathrm{LaAlO}_{3}: \mathrm{Ho}^{3+}$ phosphor. Phys. B Condens. Matter. 2008, 403, 3781-3785. [CrossRef]

26. Wang, X.; Lin, H.; Yang, D.; Lin, L.; Pun, E.Y.B. Optical transitions and upconversion fluorescence in $\mathrm{Ho}^{3+} / \mathrm{Yb}^{3+}$ doped bismuth tellurite glasses. J. Appl. Phys. 2007, 101, 113535. [CrossRef]

27. Wang, L.; Cheng, X. Preparation and tribological investigation of rare earth nanofilm on single-crystal silicon substrate. J. Rare Earths. 2006, 24, 44-49. [CrossRef]

28. Malinowski, M.; Kaczkan, M.; Wnuk, A.; Szufliñska, M. Emission from the high lying excited states of $\mathrm{Ho}^{3+}$ ions in YAP and YAG crystals. J. Lumin. 2004, 106, 269-279. [CrossRef]

29. Suresh, K.; Jayasankar, C.K. Conversion of blue-green photon into NIR photons in $\mathrm{Ho}^{3+} / \mathrm{Yb}^{3+}$ co-doped zinc tellurite glasses. J. Alloys Compd. 2019, 788, 1048-1055. [CrossRef]

30. Shannon, R.D. Revised effective ionic radii and systematic studies of interatomic distances in halides and chalcogenides. Acta Crystallogr. A 1976, 32, 751-767. [CrossRef]

31. Akazawa, H. Characterization of $\mathrm{Bi}_{2} \mathrm{O}_{3}$ thin films for doping photoluminescent $\mathrm{Er}^{3+}$ ions. Ceram. Int. 2020, in press. [CrossRef]

32. Hillie, K.T.; Swart, H.C. Electron beam induced degradation of a pulsed laser deposited ZnS:Cu,Au,Al thin film on a Si (100) substrate. Appl. Surf. Sci. 2001, 183, 304-310. [CrossRef]

33. Ollinger, M.; Cracium, V.; Nagore, S.; Senna, M.; Singh, R.K. Enhanced cathodoluminescent properties of nanoencapsulated zinc sulfide phosphors, electrochem. Solid State Lett. 2006, 9, G80. [CrossRef]

34. Gupta, A. Pulsed Laser Deposition of Thin Films; Chrisey, D.B., Hubler, G.K., Eds.; Wiley: New York, NY, USA, 1994; p. 265.

35. Hillie, K.T.; Curren, C.; Swart, H.C. ZnS thin films grown on Si (100) by XeCl pulsed laser ablation. Appl. Surf. Sci. 2001, 177, 73-77. [CrossRef]

36. Patil, R.B.; Yadav, J.B.; Puri, R.K.; Puri, V. Optical properties and adhesion of air oxidized vacuum evaporated bismuth thin films. J. Phys. Chem. Solids 2007, 68, 665-669. [CrossRef]

37. Gujar, T.P.; Shinde, V.R.; Lokhande, C.D.; Mane, R.S.; Han, S.H. Bismuth oxide thin films prepared by chemical bath deposition (CBD) method: Annealing effect. Appl. Surf. Sci. 2005, 250, 161-167. [CrossRef] 
38. Lunca Popa, P.; Sønderby, S.; Kerdsongpanya, S.; Lu, J.; Arwin, H.; Eklund, P. Structural, morphological, and optical properties of $\mathrm{Bi}_{2} \mathrm{O}_{3}$ thin films grown by reactive sputtering. Thin Solid Films. 2017, 624, 41-48. [CrossRef]

39. Ahila, M.; Malligavathy, M.; Subramanian, E.; Padiyan, D.P. Controllable synthesis of $\alpha$ and $\beta-\mathrm{Bi}_{2} \mathrm{O}_{3}$ through anodization of thermally evaporated bismuth and its characterization. Solid State Ion. 2016, 298, 23-34. [CrossRef]

40. Das, N.K.; Chakrabartty, J.; Farhad, S.F.U.; Sen Gupta, A.K.; Ikball Ahamed, E.M.K.; Rahman, K.S.; Wafi, A.; Alkahtani, A.A.; Matin, M.A.; Amin, N. Effect of substrate temperature on the properties of RF sputtered CdS thin films for solar cell applications. Results Phys. 2020, 17. [CrossRef]

41. Nefzi, C.; Souli, M.; Cuminal, Y.; Kamoun-Turki, N. Effect of substrate temperature on physical properties of $\mathrm{Cu}_{2} \mathrm{FeSnS}_{4}$ thin films for photocatalysis applications. Mater. Sci. Eng. B 2020, 254. [CrossRef]

42. Li, X.Y.; Li, H.J.; Wang, Z.J.; Xia, H.; Xiong, Z.Y.; Wang, J.X.; Yang, B.C. Effect of substrate temperature on the structural and optical properties of $\mathrm{ZnO}$ and $\mathrm{Al}$-doped $\mathrm{ZnO}$ thin films prepared by DC magnetron sputtering. Opt. Commun. 2009, 282, 247-252. [CrossRef]

43. Zhou, H.B.; Zhang, H.Y.; Tan, M.L.; Wang, Z.G. Effects of substrate temperature on the efficiency of hydrogen incorporation on the properties of Al-doped ZnO films. Superlattices Microstruct. 2012, 51, 644-650. [CrossRef]

44. Wang, F.H.; Tzeng, H.T.; Huang, C.C. Effects of deposition temperature on the properties of Ga-doped ZnO thin films. J. Sci. Innov. 2014, 4, 7-12.

45. Jeganath, K.; Choudhari, N.J.; Shruthi Pai, G.; Rao, A.; Raviprakash, Y. Role of substrate temperature on spray pyrolysed metastable $\pi$-SnS thin films. Mater. Sci. Semicond. Process. 2020, 113. [CrossRef]

46. Kumar, V.; Ntwaeaborwa, O.M.; Swart, H.C. Effect of oxygen partial pressure during pulsed laser deposition on the emission of Eu doped ZnO thin films. Phys. B Condens. Matter. 2020, 576. [CrossRef]

47. Jian, S.R.; Chen, H.G.; Chen, G.J.; Jang, J.S.C.; Juang, J.Y. Structural and nanomechanical properties of $\alpha$-plane $\mathrm{ZnO}$ thin films deposited under different oxygen partial pressures. Curr. Appl. Phys. 2012, 12, 849-853. [CrossRef]

48. Arunachalam, A.; Dhanapandian, S.; Manoharan, C.; Sridhar, R. Characterization of sprayed $\mathrm{TiO}_{2}$ on $\mathrm{ITO}^{2}$ substrates for solar cell applications. Spectrochim. Acta Part A Mol. Biomol. Spectrosc. 2015, 149, 904-912. [CrossRef]

49. Available online: https://www.materialsproject.org/materials/mp-23262 (accessed on 25 September 2020).

50. Prasada Rao, T.; Santhosh Kumar, M.C.; Safarulla, A.; Ganesan, V.; Barman, S.R.; Sanjeeviraja, C. Physical properties of $\mathrm{ZnO}$ thin films deposited at various substrate temperatures using spray pyrolysis. Phys. B Condens. Matter. 2010, 405, 2226-2231. [CrossRef]

51. Porte, Y.; Maller, R.; Faber, H.; AlShareef, H.N.; Anthopoulos, T.D.; McLachlan, M.A. Exploring and controlling intrinsic defect formation in $\mathrm{SnO}_{2}$ thin films. J. Mater. Chem. C. 2015, 4, 758-765. [CrossRef]

52. Wang, Y.; Zhao, J.; Zhou, B.; Zhao, X.; Wang, Z.; Zhu, Y. Three-dimensional hierarchical flowerlike microstructures of $\alpha-\mathrm{Bi}_{2} \mathrm{O}_{3}$ constructed of decahedrons and rods. J. Alloys Compd. 2014, 592, 296-300. [CrossRef]

53. Choi, C.G.; No, K.; Lee, W.J.; Kim, H.G.; Jung, S.O.; Lee, W.J.; Kim, W.S.; Kim, S.J.; Yoon, C. Effects of oxygen partial pressure on the microstructure and electrical properties of indium tin oxide film prepared by D.C. magnetron sputtering. Thin Solid Films. 1195, 258, 274-278. [CrossRef]

54. Iwaya, K.; Ohsawa, T.; Shimizu, R.; Okada, Y.; Hitosugi, T. Atomic-scale visualization of oxide thin-film surfaces. Sci. Technol. Adv. Mater. 2018, 19, 282-290. [CrossRef] [PubMed]

55. Jiang, Z.Z.; Guan, Z.; Yang, N.; Xiang, P.H.; Qi, R.J.; Huang, R.; Yang, P.X.; Zhong, N.; Duan, C.G. Epitaxial growth of $\mathrm{BiFeO}_{3}$ films on $\mathrm{SrRuO}_{3} / \mathrm{SrTiO}_{3}$. Mater. Charact. 2017, 131, 217-223. [CrossRef]

56. Patil, R.A.; Wei, M.K.; Yeh, P.H.; Liang, J.B.; Gao, W.T.; Lin, J.H.; Liou, Y.; Ma, Y.R. Size-controllable synthesis of $\mathrm{Bi} / \mathrm{Bi}_{2} \mathrm{O}_{3}$ heterojunction nanoparticles using pulsed $\mathrm{Nd}$ :YAG laser deposition and metal-semiconductor-heterojunction-assisted photoluminescence. Nanoscale 2016, 8, 3565-3571. [CrossRef] [PubMed]

57. Jiménez, H.; Restrepo, E.; Devia, A. Effect of the substrate temperature in ZrN coatings grown by the pulsed arc technique studied by XRD. Surf. Coat. Technol. 2006, 201, 1594-1601. [CrossRef]

58. Ogugua, S.N.; Swart, H.C.; Ntwaeaborwa, O.M. Effects of deposition environment and temperature on photoluminescence, particle morphology, and crystal structure of pulsed laser deposited $\mathrm{Ga}_{2} \mathrm{O}_{3}$ thin films. J. Vac. Sci. Technol. A. 2020, 38, 043407. [CrossRef] 
59. Sui, M.; Li, M.Y.; Kunwar, S.; Pandey, P.; Zhang, Q.; Lee, J. Effects of annealing temperature and duration on the morphological and optical evolution of self-assembled Pt nanostructures on c-plane sapphire. PLoS ONE 2017, 12, 1-18. [CrossRef] [PubMed]

60. Tay, S.T.; Jiang, X.H.; Huan, C.H.A.; Wee, A.T.S.; Liu, R. Influence of annealing temperature on ferroelectric properties of $\mathrm{SrBi}_{2} \mathrm{Ta}_{2} \mathrm{O}_{9}$ thin films prepared by off-axis radio frequency magnetron sputtering. J. Appl. Phys. 2000, 88, 5928-5934. [CrossRef]

61. Li, Y.; Zhang, S.; Sritharan, T.; Liu, Y.; Chen, T.P. Influence of oxygen partial pressure on magnetron sputtered $\mathrm{Sr}_{0.8} \mathrm{Nd}_{0.3} \mathrm{Bi}_{2.5} \mathrm{Ta}_{2} \mathrm{O}_{9+x}$ ferroelectric thin films. J. Alloys Compd. 2008, 457, 549-554. [CrossRef]

62. Campbell, A.L.; Biggers, R.R.; Subramanyam, G.; Kozlowski, G.; Kleismit, R.A.; Zate, H.N.; Hopkins, S.C.; Glowacki, B.A.; Riehl, B.D.; Peterson, T.L. Microwave characterization of nanostructured ferroelectric $\mathrm{Ba}_{0.6} \mathrm{Sr}_{0.4} \mathrm{TiO}_{3}$ thin films fabricated by pulsed laser deposition. Nanotechnology 2008, 19, 485704. [CrossRef]

63. Jena, S.; Tokas, R.B.; Tripathi, S.; Rao, K.D.; Udupa, D.V.; Thakur, S.; Sahoo, N.K. Influence of oxygen partial pressure on microstructure, optical properties, residual stress and laser induced damage threshold of amorphous $\mathrm{HfO}_{2}$ thin films. J. Alloys Compd. 2019, 771, 373-381. [CrossRef]

64. Kunti, A.K.; Sekhar, K.C.; Pereira, M.; Gomes, M.J.M.; Sharma, S.K. Oxygen partial pressure induced effects on the microstructure and the luminescence properties of pulsed laser deposited $\mathrm{TiO}_{2}$ thin films. AIP Adv. 2017, 7, 015021. [CrossRef]

65. John, J.; Chalana, S.R.; Prabhu, R.; Mahadevan Pillai, V.P. Effect of oxygen pressure on the structural and optical properties of $\mathrm{BaSnO}_{3}$ films prepared by pulsed laser deposition method. Appl. Phys. A Mater. Sci. Process. 2019, 125, 1-14. [CrossRef]

66. Ali, A.G.; Dejene, B.F.; Swart, H.C. The influence of oxygen partial pressure on material properties of $\mathrm{Eu}^{3+}$-doped $\mathrm{Y}_{2} \mathrm{O}_{2} \mathrm{~S}$ thin film deposited by pulsed laser deposition. Phys. B Condens. Matter. 2016, 480, 174-180. [CrossRef]

67. Liang, C.H.; Chen, S.C.; Qi, X.; Chen, C.S.; Yang, C.C. Influence of film thickness on the texture, morphology and electro-optical properties of indium tin oxide films. Thin Solid Films 2010, 519, 345-350. [CrossRef]

68. Zhang, X.; Ren, W.; Shi, P.; Chen, X.; Wu, X. Effect of oxygen pressure on structure and properties of $\mathrm{Bi}_{1.5} \mathrm{Zn}_{1.0} \mathrm{Nb}_{1.5} \mathrm{O}_{7}$ pyrochlore thin films prepared by pulsed laser deposition. Appl. Surf. Sci. 2010, 256, 1861-1866. [CrossRef]

69. Moulder, J.F.; Stickle, W.F.; Sobol, P.E.; Bomben, K.D. Handbook of X-Ray Photoelectron Spectroscopy; Chastain, J., Ed.; Perkin-Elmer Corporation Physical Electronics Division: Eden Prairie, MN, USA, 1992.

70. Bian, Z.; Zhu, J.; Wang, S.; Cao, Y.; Qian, X.; Li, H. Self-assembly of active $\mathrm{Bi}_{2} \mathrm{O}_{3} / \mathrm{TiO}_{2}$ visible photocatalyst with ordered mesoporous structure and highly crystallized anatase. J. Phys. Chem. C 2008, 112, 6258-6262. [CrossRef]

71. Ye, L.; Zan, L.; Tian, L.; Peng, T.; Zhang, J. The $\{001\}$ facets-dependent high photoactivity of BiOCl nanosheets. Chem. Commun. 2011, 47, 6951-6953. [CrossRef]

72. Xue, W.; Wang, Z.; Liang, Y.; Xu, H.; Liu, L.; Dong, J. Promoting role of bismuth on hydrotalcite-supported platinum catalysts in aqueous phase oxidation of glycerol to dihydroxyacetone. Catalysts 2018, 8, 20. [CrossRef]

73. Thorat, A.V.; Ghoshal, T.; Carolan, P.; Holmes, J.D.; Morris, M.A. Defect chemistry and vacancy concentration of luminescent europium doped ceria nanoparticles by the solvothermal method. J. Phys. Chem. C 2014, 118, 10700-10710. [CrossRef]

74. Luo, X.; Zhu, G.; Peng, J.; Wei, X.; Hojamberdiev, M.; Jin, L.; Liu, P. Enhanced photocatalytic activity of Gd-doped porous $\beta-\mathrm{Bi}_{2} \mathrm{O}_{3}$ photocatalysts under visible light irradiation. Appl. Surf. Sci. 2015, 351, 260-269. [CrossRef]

75. Iljinas, A.; Burinskas, S.; Dudonis, J. Synthesis of bismuth oxide thin films deposited by reactive magnetron sputtering. Acta Phys. Pol. A 2011, 120, 60-62. [CrossRef]

76. Köhler, R.; Siebert, D.; Kochanneck, L.; Ohms, G.; Viöl, W. Bismuth oxide faceted structures as a photocatalyst produced using an atmospheric pressure plasma jet. Catalysts 2019, 9, 533. [CrossRef]

77. Hsu, J.C.; Chiang, Y.S. Influence of oxygen on zinc oxide films fabricated by ion-beam sputter deposition. Int. Sch. Res. Not. 2013, 2013, 7. [CrossRef]

78. Guo, L.; Wang, Y.; Zhang, J.; Wang, Y.; Dong, P. Near-infrared quantum cutting in $\mathrm{Ho}^{3+}$, $\mathrm{Yb}^{3+}$-codoped $\mathrm{BaGdF}_{5}$ nanoparticles via first- and second-order energy transfers. Nanoscale Res. Lett. 2012, 7, 1-7. [CrossRef] [PubMed] 
79. Zhang, L.; Loiko, P.; Serres, J.M.; Kifle, E.; Lin, H.; Zhang, G.; Vilejshikova, E.; Dunina, E.; Kornienko, A.; Fomicheva, L.; et al. Growth, spectroscopy and first laser operation of monoclinic $\mathrm{Ho}^{3+}: \mathrm{MgWO}_{4}$ crystal. J. Lumin. 2019, 213, 316-325. [CrossRef]

80. Rani, P.R.; Venkateswarlu, M.; Swapna, K.; Mahamuda, S.; Prasad, M.V.V.K.S.; Rao, A.S. Spectroscopic and luminescence properties of $\mathrm{Ho}^{3+}$ ions doped Barium Lead Alumino Fluoro Borate glasses for green laser applications. Solid State Sci. 2020, 102, 106175. [CrossRef]

81. Choudhury, B.; Choudhury, A. Oxygen vacancy and dopant concentration dependent magnetic properties of Mn doped $\mathrm{TiO}_{2}$ nanoparticle. Curr. Appl. Phys. 2013, 13, 1025-1031. [CrossRef]

Publisher's Note: MDPI stays neutral with regard to jurisdictional claims in published maps and institutional affiliations.

(C) 2020 by the authors. Licensee MDPI, Basel, Switzerland. This article is an open access article distributed under the terms and conditions of the Creative Commons Attribution (CC BY) license (http://creativecommons.org/licenses/by/4.0/). 